\title{
A Comprehensive Literature Review of Acceptance and Usage Studies in the Social Commerce Field
}

\author{
Nasibeh Pouti \\ Allameh Tabataba'i University \\ pouti.np@gmail.com \\ Mohammad Taghi Taghavifard \\ Allameh Tabataba'i University \\ dr.taghavifard@gmail.com \\ Mohammad Reza Taghva \\ Allameh Tabataba'i University \\ taghva@atu.ac.ir \\ Mohammad Fathian \\ Iran University of Science and Technology \\ fathian@iust.ac.ir
}

\begin{abstract}
Different studies have considered social commerce as a new paradigm in the field of business and commerce for about a decade and addressed the identification of factors affecting its acceptance. The present study sought to thoroughly review previous research related to the adoption of social commerce. For this purpose, a systematic review of the literature was used with primary and secondary search strategies by utilizing two approaches. First, two hundred sources were reviewed using criteria such as business transactions, social commerce approach, the applied social media, customer engagement cycle, value creation and value co-creation methods, as well as the type of business based on product or service offerings, the innovation space, the employed fundamental theories, and the research method of the studies. Then, the trends and findings from the observed results in the quantitative approach were analysed, followed by distinguishing three generations of social commerce acceptance studies that were conducted over this decade. The results revealed that trust, perceived usefulness, and socialization skills have the greatest impact on social commerce acceptance. Among the various platforms, social networks and microblogs, as well as some e-commerce sites equipped with social constructs were the most used cases in social commerce. The applied theories and models in acceptance studies varied extensively while the technology acceptance model, and the theories related to the planned behaviour, rational action, and social support were frequently used. In addition, different studies focused on user behaviour and the cognitive space of innovation and business-tocustomer transactions, which mainly evaluated the sale of goods through social commerce while the scope of service provision was less prominent. Regarding the research method, most of the studies were non-experimental, descriptive, and survey and the main sources of the dissemination of social commerce acceptance research were journal articles.
\end{abstract}

Keywords: Social Commerce, Acceptance, Systematic Literature Review 


\section{INTRODUCTION}

The rapid advent and advancement of social media and Web 2.0 have provided a wonderful potential to convert e-commerce from a product-oriented environment to a social-based and customer-centered field [1]. Social media basically refers to Internetbased applications built on Web 2.0 while Web 2.0 refers to a concept and a platform for collective intelligence utilization [2]. In this context, social sciences and experiences are available for the customers, which support them for better understanding their online buying purposes, as well as making more conscious and correct purchase decisions [3]. Further, all online businesses can capture the customers' behaviour, which gives them intuitions into their shopping experiences and expectations and help them to develop successful business guidelines [4]. Therefore, users should adopt social commerce as an innovation. The acceptance of innovation is considered as a process, which results in initiating the use of a product, process, or application.

The adoption of innovation typically involves a three-step process including its preacceptance, acceptance, and persistence, which is the output of the stage of decisionmaking and willingness for acceptance. So far, innovation research has been technology-centric in history since its origins are economic issues and technology management [5][6].

The motivation for the present study was to analyze the studies of social commerce acceptance. To this end, the sources of interest for the two groups of audience were evaluated based on the interest of the target audiences of the present study including the first category of audience seeking to gain commercial advantage through social commerce. Studies can open the door to these audiences and guide them through relevant research by analyzing the following issues.

- The type of social media under consideration;

- The type of applied business transaction;

- The thematic focus area;

- The type of social commerce focus on the customer engagement cycle;

- Value creation and value co-creation through social commerce;

- The focus of studies on function areas;

- The extent of the focus of studies on product buying or service provision;

- Social commerce approach;

- A focus on the geographical and temporal focus of social commerce

The second category belongs to the audience seeking methods to embrace innovation and view social commerce as an innovation needed for adoption. These people are normally the researchers who attempt to steer society toward the right alignment with innovation. The evaluation of adoption stages, innovation spaces, the applied basic theories, as well as effective and influential factors, the types of research methods, and research outputs can help the audience and guide them for research.

To this end, a systematic literature review (SLR) and the research were conducted based on research questions which were purposefully designed to address the interests of these two groups of audience. Furthermore, two quantitative and qualitative approaches were utilized to systematically review the resources. In the quantitative approach, the concerned metrics are typically categorized by the time or subject. Furthermore, the 
qualitative approach attempts to describe the obtained trends and analyses in the three generations of studies related to social commerce acceptance. These three generations represent the rapid changes over the last decade regarding accepting social commerce. Finally, the research gaps were evaluated based on the observed trends and several implications were recommended as well.

The present exploratory systematic review aimed to find all the scientific studies which evaluated social commerce adoption during 2010-2018. During the planning phase of the present SLR and using a pilot study, the following questions were developed for data extractions.

Q1. What are the theoretical foundations of social commerce acceptance studies?

Q2. What is the approach taken in social commerce acceptance studies based on the applied platform?

Q3. What are the types of research methods used in social commerce acceptance studies?

Q4. What are the considerations for business, customers, and innovation space in social commerce acceptance studies?

Q5. What is the geographical focus of social commerce acceptance studies?

A quantitative and qualitative analysis approach was used to answer the abovementioned questions. The quantitative analysis dealt with the multiplicity of components and the time distribution of applications and the qualitative analysis sought to discover the observed trends and the evolution of social media use in businesses.

The intended indicators in the quantitative analysis included the components which demonstrated the differentiation of studies such as the focus on the type of the applied media, business approach to media use, business transactions. Additionally, the other components encompassed the used basic theories, the type of focus on the adoption process, attention to the customer engagement cycle, and the stages of value creation and value co-creation.

The observed trends and the results were qualitatively analyzed after performing quantitative analysis. The gap analysis is considered as one of the important outputs of the analysis phase in this research, which can be considered in future studies.

\section{SYSTEMATIC LITERATURE REVIEW PLAN}

Based on the evidence-based software engineering (EBSE) policy, three phases were proposed for the systematic review of literature including planning, implementation, and reporting the results [7]. During the planning phase, an official protocol was created to conduct a systematic review of the literature. This protocol contained the details of the research strategy, which was based on research questions, inclusion/exclusion criteria, quality assessment criteria, data extraction strategy, along with data synthesis and analysis guidelines [8].

The protocol was pilot tested for evaluating the perfectness of the search string and the correctness of inclusion/exclusion criteria and data extraction guidelines of the present study [9]. After pilot testing, the updated version of the protocol was sent to two external reviewers who were considered as experts in the field. The reviewers recommended some changes regarding the research question, followed by incorporating inclusion/exclusion criteria related to the scope of SLR into the protocol. Then, the steps of the protocol were redefined during the implementation phase. The following subsections explain the planning phase of the review. 


\subsection{Primary Search Guidelines}

The primary search guidelines included the following steps:

1. Extracting the main search terms based on research questions;

2. Performing a pilot study to extract relevant terms, as well as synonyms and substitution options which were used in some literature (Table 1);

3. Concatenating terminology using the Boolean operators to create a search string (Table 2);

4. Performing search based on the Boolean string obtained in a search engine like Google, leading to numerous scientific databases;

5. Hand-checking manually the results of the search until the density of the obtained results on each page was zero;

6. Selecting a range of online databases, journal archives, and conference proceedings for the initial analysis of the search results;

7. Retrieving the citations and abstracts of the results and managing these features using the EndNote.

Considering the research question, the following three major terms were identified for the searching process, including social commerce, adoption, and customer. Based on the major search terms, the alternative terms were identified (Table 1) and the terms were linked to formulating the search string. In addition, the string was customized for different online databases based on their interface requirements while keeping the logical order consistent.

Table 1. Search terms and their synonyms

\begin{tabular}{lll}
\hline Search Terms & Synonyms & Surrogates \\
\hline Social Commerce & & Social Network Commerce-Social Media Commerce \\
\hline Adoption & Diffusion & Acceptance-Adaptation-Conformity \\
\hline Customer & Consumer & End User-User \\
\hline On Abstract (Social Commerce OR Social Network Commerce OR Social Media Commerce) AND \\
(Adoption OR Acceptance OR Adaptation OR Conformity) AND (Customer OR Consumer OR User \\
\hline
\end{tabular}

It is worth noting that searching was not limited to the publication year during the primary search process. Regarding the search process, the meanings in the studies conducted before 2010 were extremely old and highly archaic studies were considered for the review. Therefore, 2010 was selected as the starting year in the present study.

\subsubsection{Study on Selection Criteria}

The obtained results based on the early search strategy were filtered by using criteria in order to eliminate unrelated studies. The search results were shifted based on the following steps:

Step 1. The results of the initial strategy were reviewed through their abstracts and studies with the following characteristics were sieved from the results.

- Non-English studies;

- In general, unrelated studies which were restored due to the poor performance of the search string by the search engine;

- Head articles, tutorials, poster sessions, centers, previews, and comments; 
- Articles published before 2010 .

Step 2. Based on the papers obtained from Step 1, the abstracts were evaluated only to exclude studies which had the following characteristics:

- Not directly or indirectly related to the field of social commerce or the adoption of social media in the business;

- Not following any empirical research method;

- Ph.D. dissertation and master theses published from the research covered by the theses were available and included in the review.

Step 3. Duplicate articles were removed from the previous citation by selecting the selected filter. However, the conferences and editions of the publications were reviewed for repetitive publications and only the articles of the journals or articles with more details of the study were selected, which included the final results.

Although the present study failed to review the quality of the articles at this stage, it determined and dealt with the quality of the evaluation and data extraction of articles which were of poor quality or scientific or literary theft.

\subsection{Secondary Search Guidelines}

To ensure not to lose any of the related studies, secondary search guidelines were designed by conducting the following steps:

Step 1: The references of all included studies were reviewed based on the retrieved results. Then, all the qualified citations were applied with the same selection criteria.

Step 2: Regarding the results in Step 1 of the secondary search, the subject of social commerce was found more comprehensively published in Information Systems, Business and Management Research, and Electronic Commerce journals instead of Computer Science and Software Engineering. Therefore, the search scope was developed by using these journals. An online search was conducted on the archives of the journals including Information Management, Electronic Commerce Research and Applications, Technological Forecasting and Social Change, Information and Management, Electronic Commerce, Information Management, Business Research, Management Information Systems, Management Science, Decision Support Systems, and Management Research.

Step 3: Further, the DBLP publication profiles of some scholars (e.g., Hajli, Liang, Chen, Wang, Shanmugam, Zhang, Yadav, Zhao, and Benyoucef) were reviewed, who were highly cited for their research work on social commerce adoption. The DBLP computer science bibliography is the on-line reference for bibliographic information on major computer science publications. Furthermore, it has evolved from an early small experimental webserver to a popular open-data service for the entire computer science community. The mission of DBLP is to support computer science researchers in their daily efforts by providing free access to high-quality bibliographic meta-data and links to the electronic editions of publications.

Step 4: Finally, six published literature reviews in reputable journals and valid conferences during the last decades were selected to ensure the inclusion of all related papers [10-15]. Then, all references (from 2010 onward) in those literature reviews and papers were sought, which were qualified for consideration and treated with the same three-step selection criteria that were described in Section 3.1.1. 


\subsection{Quality Assessment}

The quality of the qualified studies was evaluated based on the applied research method, as well as the quality of their reported results since these data were the only available alternative of quality assessment [16]. In general, quality assessment was performed based on three stages as follows.

Study Quality: In this step, the quality assessment checklist was used by considering the EBSE guidelines in the previously conducted SLR [9]. This checklist included general and special sections based on the research method encompassing a survey, case study, along with experiment and experience reports. All studies scored equal to or greater than 50\% were considered in the present review and the remaining cases were eliminated accordingly.

Publication Quality: The journal impact factor was utilized based on the ranking of 2018 in order to appraise the quality of the outlet where the papers were published, followed by reviewing only those articles with an impact factor greater than 1 .

Assessment of the Impact of the Paper: In this stage, article citations were checked through Google Scholar to evaluate the impact of the published papers.

Assessment of the Other Resources: Considering four types of sources including the journal article, conference paper, chapter book, and thesis, evaluating the quality of sources other than the journal article was necessary. Thus, the selection of the book chapters, the author, the publications, and the direct relation with the subject were considered as the criteria for selection. Additionally, the level of the science of respective universities was the criterion for selecting the theses. Eventually, conference selection criteria included conference organizer, scientific committee, conference internationality, valid conference index, and thematic relationship with social commerce.

\subsection{Data Extraction}

Three types of data including publication details, context description, and findings were extracted based on the guidance provided in the previous research [17]. In addition, publication details included titles, authors, journal/conference/book chapters/thesis information, and the impact factor of the journal, conference index, and the year of publication. Further, context description encompassed a research method, data collection method, social commerce approach, social media type, business transaction, adoption types, as well as the design of data collection methods and instruments. Finally, the findings included the relationship between social commerce parameters and intention to use, influential adoption parameters, customer characteristics, and social commerce characteristics, as well as the relationship between social commerce and customer, and the geographical distribution of social commerce adoption.

\subsection{Data Synthesis and Analysis}

To answer research questions, the findings of all 203 studies were analysed to extract their outcomes regarding the social commerce-adoption relationship. The results of the scientific inquiry into 203 studies were categorized into four segments. The first segment was related to the adoption stage with four areas including the paper title, preadoption stage, adoption stage, and post-adoption stage. The adoption type was identified based on the keywords in the abstract, introduction, and research model. The second segment belonged to the parameters affecting and being affected by social 
commerce adoption. The third segment encompassed the fundamental theory, and finally, the fourth segment elaborated on the research method, data collection method, data analysis method, data analysis tools, and the sample size. The results including adoption phases, basic theories, social commerce approach, research methods and instruments, business transactions, geography focus, reference types, thematic focus, and the innovation space were extracted based on the evaluation of research works and data synthesis.

\subsection{Database Creation}

For the quantitative and qualitative analysis of the results, a database of 14 entities was used, which was created based on data from a systematic review. These entities included adoption stages, applied theories, research methods, as well as the statistical population of research, research publications, research geography, social commerce approach, business transactions, acceptance factors, value co-creation, customer engagement cycle, research focus, and innovation space.

Each entity was created as a table containing the fields of interest based on the type of qualitative and quantitative analysis of a particular entity. The fields of each table were as follows.

Adoption Stage Table: The research title, year of research, pre-adoption, and adoption, post-adoption;

Applied Theory Table: The research title, year of research, along with applied theories, models, and frameworks;

Research Method Table: The research title, year of research, and the type of research (i.e., first, second, and third levels);

Statistical Society Table: The research title, year of research in addition to the applied statistical society, statistical sample, and social media;

Research Publication Table: The research title, year of research, type of publication, name of the publication, and author(s)'s name;

Research Geography Table: The research title, year of research, country of research, and research continent;

Social Commerce Approach Table: The research title, year of research, and social commerce approach;

Business Transactions Table: The research title, year of research, type of transaction, and type of business;

Acceptance Factor Table: The research title, year of research, affecting factors, and affective factors;

Value Co-creation Table: The research title, year of research, and value co-creation stage;

Customer Engagement Cycle Table: The research title, year of research, and customer engagement stage;

Research Focus Table: The research title, year of research, as well as focus on the user, transaction, business, environment, technology, and organization;

Innovation Space Table: The research title, year of research, along with cognitive, informational, and social spaces 


\section{RESULTS}

\subsection{Social Commerce Approach}

In general, two approaches can be addressed to use social commerce. The first approach uses technology instruments through social media and incorporates business processes. The second approach is related to the time the social constructs are transferred to the electronic platform of business processes. However, both approaches are observed in the studies conducted on accepting social commerce. For example, social media such as Facebook, Twitter, LinkedIn, and the like are visible in the social media instruments which are employed for business and commerce processes, as well as commercial websites such as HP, Coca-Cola, Amazon, Groupon, and others cases which use the second approach. Table 2 presents the types of platforms in social commerce acceptance research based on the type of the applied approach and the extent of using each platform in the studies.

Table 2. Social commerce approaches based on the social commerce platform

\begin{tabular}{|c|c|c|c|c|}
\hline $\begin{array}{l}\text { Social } \\
\text { Commerce Platform }\end{array}$ & Type of Platform & Social Commerce Approach & Count & Percent \\
\hline Fashion Bug & Website & Electronic Commerce + Social Constructs & 1 & 0.52 \\
\hline Odel & Website & Electronic Commerce + Social Constructs & 1 & 0.52 \\
\hline Coupang & Website & Electronic Commerce + Social Constructs & 3 & 1.56 \\
\hline Wemakerprice & Website & Electronic Commerce + Social Constructs & 2 & 1.04 \\
\hline Hellodc & Website & Electronic Commerce + Social Constructs & 1 & 0.52 \\
\hline Wal-Mart & Website & Electronic Commerce + Social Constructs & 2 & 1.04 \\
\hline Best Buy & Website & Electronic Commerce + Social Constructs & 1 & 0.52 \\
\hline Amazon & Website & Electronic Commerce + Social Constructs & 4 & 2.08 \\
\hline Tickmonster & Website & Electronic Commerce + Social Constructs & 3 & 1.56 \\
\hline bj.jumei & Website & Electronic Commerce + Social Constructs & 1 & 0.52 \\
\hline GFlock & Website & Electronic Commerce + Social Constructs & 1 & 0.52 \\
\hline House of Fashion & Website & Electronic Commerce + Social Constructs & 1 & 0.52 \\
\hline Nolimit & Website & Electronic Commerce + Social Constructs & 1 & 0.52 \\
\hline ZigZag.lk & Website & Electronic Commerce + Social Constructs & 1 & 0.52 \\
\hline Kelly Felder & Website & Electronic Commerce + Social Constructs & 1 & 0.52 \\
\hline TripAdvisor & Website & Electronic Commerce + Social Constructs & 3 & 1.56 \\
\hline eBay & Website & Electronic Commerce + Social Constructs & 3 & 1.56 \\
\hline Target and Overstock & Website & Electronic Commerce + Social Constructs & 1 & 0.52 \\
\hline Groupon & Website & Electronic Commerce + Social Constructs & 4 & 2.08 \\
\hline Librarything & Website & Electronic Commerce + Social Constructs & 1 & 0.52 \\
\hline Target & Website & Electronic Commerce + Social Constructs & 1 & 0.52 \\
\hline Overstock & Website & Electronic Commerce + Social Constructs & 1 & 0.52 \\
\hline Coca Cola & Website & Electronic Commerce + Social Constructs & 1 & 0.52 \\
\hline HP & Website & Electronic Commerce + Social Constructs & 1 & 0.52 \\
\hline Dell & Website & Electronic Commerce + Social Constructs & 1 & 0.52 \\
\hline Orbits & Website & Electronic Commerce + Social Constructs & 1 & 0.52 \\
\hline 1800flowers & Website & Electronic Commerce + Social Constructs & 1 & 0.52 \\
\hline Crutchfield & Website & Electronic Commerce + Social Constructs & 1 & 0.52 \\
\hline Foresquare & Website & Electronic Commerce + Social Constructs & 2 & 1.04 \\
\hline Ctrip & Website & Electronic Commerce + Social Constructs & 1 & 0.52 \\
\hline Hoteles & Website & Electronic Commerce + Social Constructs & 1 & 0.52 \\
\hline Starbooks & Website & Electronic Commerce + Social Constructs & 1 & 0.52 \\
\hline Opensky & Social Network & Social Media + Business Process & 1 & 0.52 \\
\hline Facebook Starbucks & Social Network & Social Media + Business Process & 1 & 0.52 \\
\hline
\end{tabular}


Table 2. Social commerce approaches based on the social commerce platform (cont.)

\begin{tabular}{|c|c|c|c|c|}
\hline $\begin{array}{l}\text { Social } \\
\text { Commerce Platform }\end{array}$ & Type of Platform & Social Commerce Approach & Count & Percent \\
\hline Zing & Social Network & Social Media + Business Process & 1 & 0.52 \\
\hline t.dianping & Social Network & Social Media + Business Process & 1 & 0.52 \\
\hline Cloob & Social Network & Social Media + Business Process & 1 & 0.52 \\
\hline Pinterest & Social Network & Social Media + Business Process & 2 & 1.04 \\
\hline Facebook Lady Gaga & Social Network & Social Media + Business Process & 1 & 0.52 \\
\hline LinkedIn & Social Network & Social Media + Business Process & 8 & 4.16 \\
\hline Meilishuo & Social Network & Social Media + Business Process & 1 & 0.52 \\
\hline Myspace & Social Network & Social Media + Business Process & 5 & 2.6 \\
\hline Renren & Social Network & Social Media + Business Process & 3 & 1.56 \\
\hline Facebook Green Day & Social Network & Social Media + Business Process & 1 & 0.52 \\
\hline Facebook & Social Network & Social Media + Business Process & 46 & 23.92 \\
\hline $51 . \mathrm{com}$ & Social Network & Social Media + Business Process & 1 & 0.52 \\
\hline Kaixin001 & Social Network & Social Media + Business Process & 1 & 0.52 \\
\hline Friendster & Social Network & Social Media + Business Process & 2 & 1.04 \\
\hline Orkut & Social Network & Social Media + Business Process & 1 & 0.52 \\
\hline Xanga & Social Network & Social Media + Business Process & 1 & 0.52 \\
\hline Academia & Social Network & Social Media + Business Process & 1 & 0.52 \\
\hline Google+ & Social Network & Social Media + Business Process & 1 & 0.52 \\
\hline MXit & Social Network & Social Media + Business Process & 1 & 0.52 \\
\hline Real & Social Network & Social Media + Business Process & 1 & 0.52 \\
\hline Telegram & Social Messenger & Social Media + Business Process & 1 & 0.52 \\
\hline Hangout & Social Messenger & Social Media + Business Process & 1 & 0.52 \\
\hline WhatsApp & Social Messenger & Social Media + Business Process & 1 & 0.52 \\
\hline Yahoo & Social Messenger & Social Media + Business Process & 1 & 0.52 \\
\hline SinaWeibo & Microblog & Social Media + Business Process & 8 & 4.16 \\
\hline Instagarm & Microblog & Social Media + Business Process & 3 & 1.56 \\
\hline Twitter & Microblog & Social Media + Business Process & 24 & 12.48 \\
\hline Xiaonei & Social Gaming & Social Media + Business Process & 1 & 0.52 \\
\hline GameFly & Social Gaming & Social Media + Business Process & 1 & 0.52 \\
\hline YouTube & Video Sharing & Social Media + Business Process & 9 & 4.68 \\
\hline Yelp & Online Communities & Social Media + Business Process & 1 & 0.52 \\
\hline Ning & Online Communities & Social Media + Business Process & 1 & 0.52 \\
\hline Snapshot & Image Sharing & Social Media + Business Process & 1 & 0.52 \\
\hline Flicker & Image Sharing & Social Media + Business Process & 4 & 2.08 \\
\hline Kikseen & Video Sharing & Social Media + Business Process & 1 & 0.52 \\
\hline LiveStream & Video Sharing & Social Media + Business Process & 1 & 0.52 \\
\hline UStream & Video Sharing & Social Media + Business Process & 1 & 0.52 \\
\hline Netflix & Video Sharing & Social Media + Business Process & 1 & 0.52 \\
\hline
\end{tabular}

\subsection{Types of Social Media}

Considering the various types of social media, the level of attention and utilization of a diversity of social media are considered as the most remarkable points in the study of social media.

The types of applied social media in the research included the social network, microblog, blog, wiki, RSS, social tagging, podcast, virtual communities, video sharing, and image sharing. Figure 2 depicts the extent to which studies focus on a variety of social media. Social networks are the most commonly used social media, in which microblogs and blogs are at the forefront. 


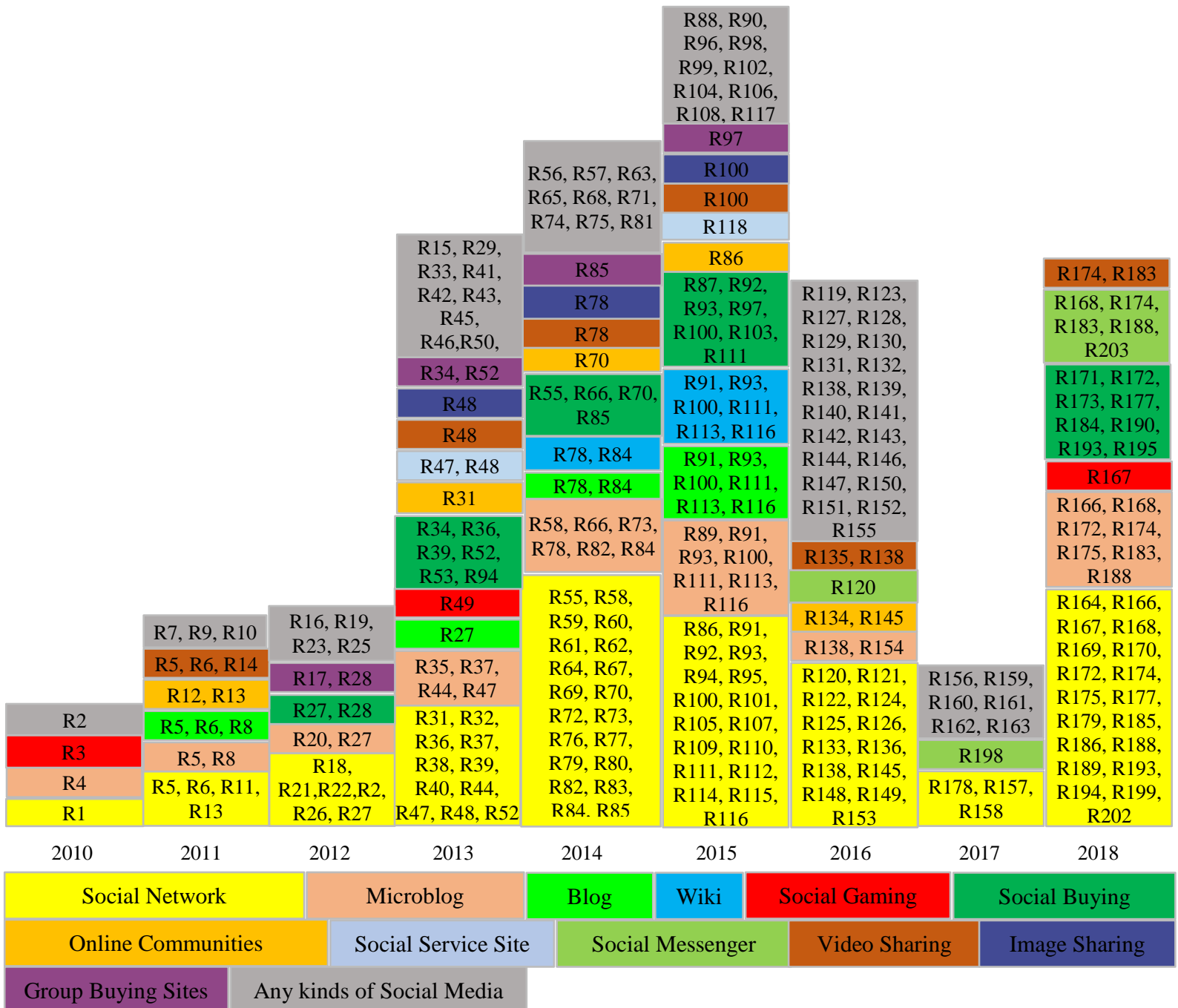

Figure 2. Temporal distribution of the types of social media used in different studies

In addition to the applied social media in commerce, another approach for social commerce encompasses sites related to social buying, social service, social gaming, and group buying, which provide goods and services with social commerce constructs such as forums and communities, rating and reviews, along with recommendation and referrals.

\subsection{Thematic Focus Area}

The use of the focus on subject area is considered as one of the methods for analysing studies, upon which some studies have focused solely on specialized business areas and the acceptance of social commerce in these areas. Some of these areas include marketing, entrepreneurship, product sales, service delivery, teamwork, and customer relationship management. Recently, several studies have addressed the user and issues such as shopping behaviour, adaptive behaviour, adoption patterns, and behavioural continuity. The third focal area is related to transaction studies including reviewing the interaction, information, social structures, and social media. Each of these domains has some sub-domains or focus areas. Figure 3 illustrates the focus area of studies, along with the number of studies conducted in each area. 


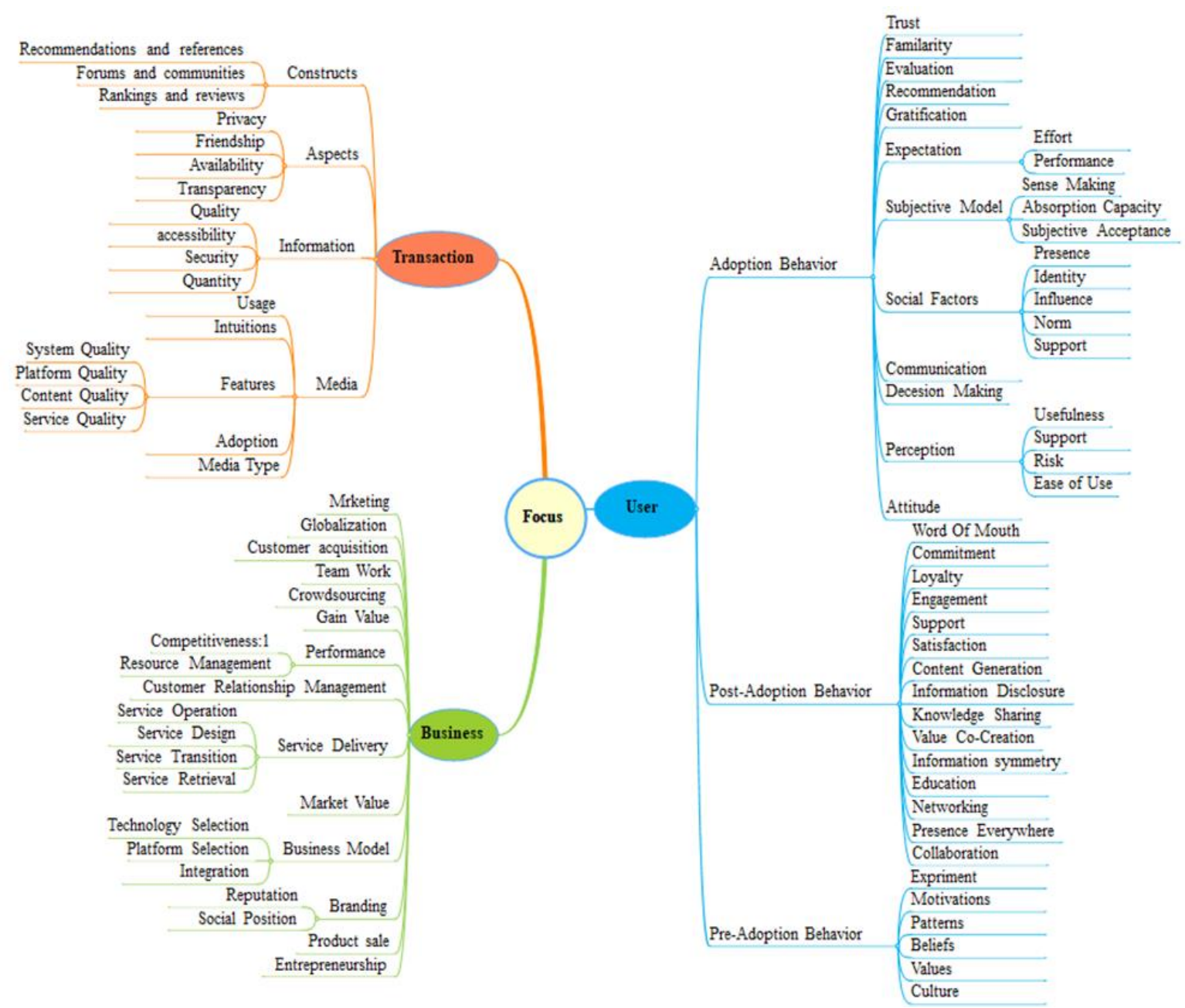

Figure 3. The mind map of the thematic focus area of social commerce adoption studies

It should be noted that some studies addressed several areas, especially at the second level, with more focused levels. Furthermore, some studies simultaneously focused on several areas, and thus the total number of studies conducted on each focus area was larger than the total number of studies.

\subsection{Value Creation and Value Co-creation}

The emergence of value creation and value co-creation through social media activities is regarded as one of the potentials of social media. The $5 \mathrm{C}$ categorization is based on the actions which are enabled by the social media instruments, including communicating, collaborating, connecting, completing, and combining. Given the purpose of the present study regarding evaluating the acceptance of social commerce, the $5 \mathrm{C}$ framework allows analysing the functions of social media in this area for value creation and co-creation. Table 3 presents the value creation and co-creation mechanisms [18]. Based on these mechanisms, various studies were evaluated and the impact of each study was determined on each of the stages of value co-creation. Accordingly, some studies focused on one of the functions while the other cases emphasized several co-creation functions. Figure 4 displays the degree of attention to each of the value co-creation stages in the studies of social commerce adoption. 
Table 3. Examples of social media applications based on a 5C categorization

\begin{tabular}{lll}
\hline 5C Function & $\begin{array}{l}\text { Typical Social Media } \\
\text { Applications Providing } \\
\text { Functionality }\end{array}$ & Purpose \\
\hline $\begin{array}{l}\text { Collaborating: Collectively } \\
\text { creating content }\end{array}$ & Wikis, shared workspaces & $\begin{array}{l}\text { Create content together, collaborate, and } \\
\text { prod usage }\end{array}$ \\
\hline $\begin{array}{l}\text { Communicating: } \\
\text { Publishing and sharing } \\
\text { content }\end{array}$ & $\begin{array}{l}\text { Blogs, media sharing systems, } \\
\text { discussion forums, micro blogs, } \\
\text { and instant messaging }\end{array}$ & $\begin{array}{l}\text { Publish, discuss, express oneself, show } \\
\text { opinions, share, influence, and store }\end{array}$ \\
\hline $\begin{array}{l}\text { Completing: Adding, } \\
\text { describing, and filtering }\end{array}$ & $\begin{array}{l}\text { Tagging, social bookmarking, } \\
\text { syndications, and add-ons }\end{array}$ & $\begin{array}{l}\text { Add metadata, describe content, subscribe } \\
\text { to updates, combine, and experience } \\
\text { serendipity }\end{array}$ \\
\hline Connecting: Networking & $\begin{array}{l}\text { Social networks, communities, } \\
\text { and virtual worlds }\end{array}$ & $\begin{array}{l}\text { Socialize, network, and connect } \\
\text { (sometimes play and entertain) }\end{array}$ \\
\hline $\begin{array}{l}\text { Combining: Mixing and } \\
\text { matching }\end{array}$ & Mash-ups and platforms & $\begin{array}{l}\text { Combine other instruments and } \\
\text { technologies based on situations and } \\
\text { needs. }\end{array}$ \\
\hline
\end{tabular}

Source: [19]

The aspects of the value creation and co-creation from the articles were analysed based on the degree to which they described the mechanisms of value creation and co-creation, as well as the extent to which the articles of various media played the roles of social recognition. The second method belonged to the use of the 5C framework for analysing social media functions in more detail and determining their provided evidence.

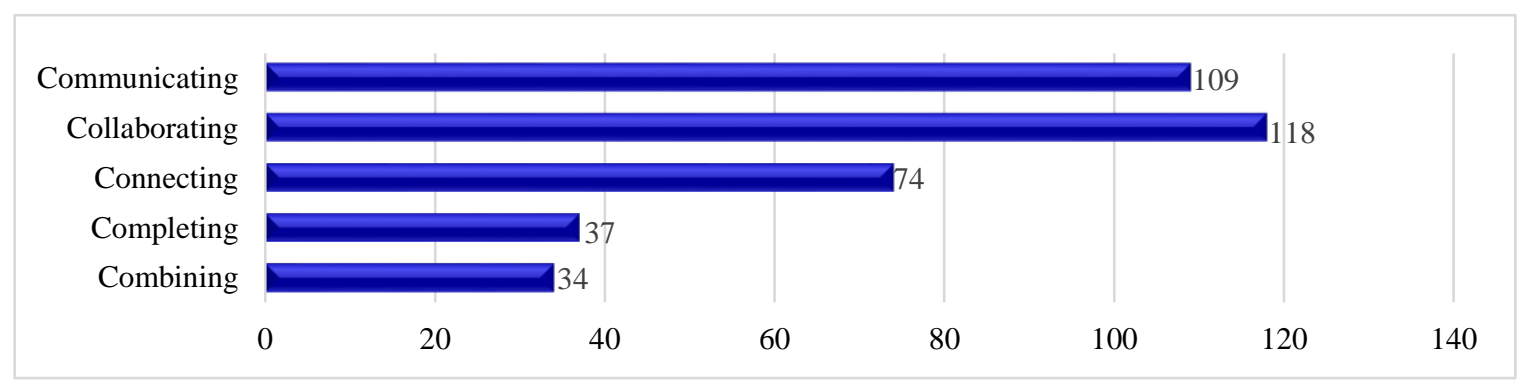

Figure 4. The extent of the studies conducted on each of the value creation mechanisms

Table 4 reports each of the value creation mechanisms by separate studies. As shown, a solid black circle is used to determine which studies identify the various social media roles and mechanisms for creating or co-creating value. Describing the studies in which the value creation or co-creation mechanisms of social media are mentioned is the sign of the empty circle although the half-full circle determines which studies evaluate the value creation or co-creation to some extent. 
Table 4. The analysis of value creation and co-creation mechanisms in social commerce adoption studies

\footnotetext{
: : Studies which elaborate on different roles and mechanisms of social media in creating or co-creating value; : Studies in which social media-related value creation or co-creation mechanisms and associated social media roles have ambiguously commented or paved the way for interpretation;

: Studies in which value creation or co-creation mechanisms or social media roles are mentioned while not being described accurately.
}

\begin{tabular}{|c|c|c|c|c|c|c|c|}
\hline \multirow{2}{*}{$\begin{array}{l}\text { Analysis of Social Media } \\
\text { Mechanisms Affecting } \\
\text { Value Creation and Co- } \\
\text { creation }\end{array}$} & \multirow[t]{2}{*}{$\begin{array}{l}\text { Value } \\
\text { Creation }\end{array}$} & \multirow[t]{2}{*}{$\begin{array}{l}\text { Value Co } \\
\text { creationn }\end{array}$} & \multicolumn{5}{|c|}{$\begin{array}{l}\text { Co- Detailed Analysis of the 5C Social Media Functions of Value Creation (Vuori, } \\
\text { 2011) }\end{array}$} \\
\hline & & & Communication & Collaborating & Connecting & Completing & Combining \\
\hline $\begin{array}{l}\text { R5,R12,R17,R41,R59,R62 } \\
\text {,R64,R76,R83,R105,R113, } \\
\text { R120,R126,R134,R148,R1 } \\
\text { 50,R160,R165,R184,R185 } \\
\text {,R186,R188 }\end{array}$ & & & $\begin{array}{l}\text { R76,R113,R120 } \\
\text {,R150,R165,R1 } \\
\text { 84,R186,R188 }\end{array}$ & $\begin{array}{l}\text { R12,R17,R41,R5 } \\
\text { 9,R62,R64,R105 } \\
\text {,R134,R160,R16 } \\
\text { 5,R184,R186 }\end{array}$ & $\begin{array}{l}\text { R113,R126,R1 } \\
50\end{array}$ & $\begin{array}{l}\text { R5,R12,R41, } \\
\text { R62,R65,R76, } \\
\text { R83,R105,R1 } \\
\text { 26,R148,R16 } \\
\text { 5,R185,R188 }\end{array}$ & $\begin{array}{l}\text { R5,R12,R41, } \\
\text { R59,R62,R65, } \\
\text { R76,R83,R10 } \\
\text { 5,R126,R148, } \\
\text { R165,R185,R } \\
188\end{array}$ \\
\hline $\begin{array}{l}\mathrm{R} 2, \mathrm{R} 10, \mathrm{R} 19, \mathrm{R} 22, \mathrm{R} 23, \mathrm{R} 24 \\
\text {,R28,R32,R34,R39,R45,R } \\
\text { 46,R57,R71,R74,R75,R80, } \\
\text { R81,R85,R96,R99,R102,R } \\
\text { 118,R121,R123,R128,R13 } \\
\text { 0,R140,R142,R144,R147, } \\
\text { R153,R154,R156,R159,R1 } \\
\text { 68,R169,R170,R176,R181 } \\
\text {,R187,R191,R192,R202 }\end{array}$ & & & $\begin{array}{l}\text { R2,R19,R23,R3 } \\
\text { 2,R45,R74,R81, } \\
\text { R99,R102,R123 } \\
\text {,R128,R140,R1 } \\
\text { 42,R144,R154, } \\
\text { R156,R168,R17 } \\
0, \mathrm{R} 181, \mathrm{R} 192, \mathrm{R} \\
202\end{array}$ & $\begin{array}{l}\text { R71,R118,R140, } \\
\text { R144,R153,R15 } \\
\text { 6,R159,R169,R1 } \\
\text { 70,R187,R191,R } \\
192\end{array}$ & $\begin{array}{l}\text { R10,R22,R24, } \\
\text { R28,R32,R39, } \\
\text { R46,R57,R74, } \\
\text { R75,R80,R85, } \\
\text { R96,R121,R13 } \\
0, R 144, R 147, \\
\text { R176,R181,R1 } \\
\text { 91,R202 }\end{array}$ & & R34,R202 \\
\hline $\begin{array}{l}\text { R1,R21,R38,R40,R48,R58 } \\
\text {,R87,R89,R92,R103,R106, } \\
\text { R109,R110,R111,R114,R1 } \\
\text { 25,R127,R129,R136,R143 } \\
\text {,R149,R151,R155,R171,R } \\
\text { 174,R175,R177,R182,R20 } \\
3\end{array}$ & & & $\begin{array}{l}\text { R21,R40,R48,R } \\
\text { 58,R89,R92,R1 } \\
\text { 10,R129,R136, } \\
\text { R143,R155,R17 } \\
\text { 4,R177,R203 }\end{array}$ & $\begin{array}{l}\text { R1,R21,R38,R48 } \\
\text {,R58,R106,R111 } \\
\text { R114,R125,R12 } \\
\text { 7,R129,R151,R1 } \\
\text { 55,R175 }\end{array}$ & $\begin{array}{l}\text { R21,R38,R87, } \\
\text { R92,R103,R10 } \\
\text { 9,R110,R149, } \\
\text { R171,R177,R1 } \\
82\end{array}$ & $\mathrm{R} 58, \mathrm{R} 203$ & R58,R203 \\
\hline $\begin{array}{l}\text { R4,R26,R27,R35,R42,R43 } \\
\text {,R47,R51,R60,R66,R69,R } \\
\text { 78,R86,R93,R98,R117,R1 } \\
\text { 22,R133,R137,R145,R157 } \\
\text {,R161,R164,R166,R173,R } \\
\text { 178,R193,R194,R197,R19 } \\
8\end{array}$ & & & $\begin{array}{l}\text { R26,R51,R86,R } \\
\text { 122,R161,R164, } \\
\text { R166,R178,R19 } \\
\text { 4,R197 }\end{array}$ & $\begin{array}{l}\text { R26,R27,R42,R5 } \\
\text { 1,R86,R98,R117 } \\
\text {,R137,R157,R16 } \\
\text { 1,R166,R173,R1 } \\
\text { 93,R194,R197 }\end{array}$ & $\begin{array}{l}\mathrm{R} 86, \mathrm{R} \\
4\end{array}$ & $\begin{array}{l}\text { R4,R35,R43, } \\
\text { R47,R51,R60, } \\
\text { R66,R69,R78, } \\
\text { R93,R133,R1 } \\
45, R 164, R 17 \\
\text { 3,R198 }\end{array}$ & $\begin{array}{l}\text { R4,R35,R43, } \\
\text { R47,R51,R60, } \\
\text { R66,R69,R78, } \\
\text { R93,R133,R1 } \\
\text { 45,R164,R17 } \\
\text { 3,R198 }\end{array}$ \\
\hline $\begin{array}{l}\text { R6,R29,R30,R67,R72,R90 } \\
\text {,R91,R97,R131,R146,R15 } \\
\text { 8,R162,R172 }\end{array}$ & & & $\begin{array}{l}\text { R6,R29,R97,R1 } \\
\text { 46,R158,R162, } \\
\text { R172 }\end{array}$ & R29,R131,R146 & $\begin{array}{l}\text { R30,R67,R90, } \\
\text { R91 }\end{array}$ & R72 & R72 \\
\hline $\begin{array}{l}\text { R3,R8,R18,R33,R49,R54, } \\
\text { R56,R65,R79,R82,R95,R1 } \\
\text { 01,R132,R138,R163,R167 }\end{array}$ & & & $\begin{array}{l}\text { R33,R54,R56,R } \\
\text { 65,R79,R95,R1 } \\
01, \mathrm{R} 163, \mathrm{R} 167 \\
\end{array}$ & $\begin{array}{l}\text { R18,R82,R95,R1 } \\
32\end{array}$ & $\begin{array}{l}\text { R3,R33,R49,R } \\
163, \mathrm{R} 167\end{array}$ & R8,R33,R138 & $\begin{array}{ll}\text { R8,R33,R138 } \\
\end{array}$ \\
\hline $\begin{array}{l}\text { R13,R16,R70,R108,R139, } \\
\text { R189,R190,R195,R196,R2 } \\
\text { 01 }\end{array}$ & & & $\begin{array}{l}\text { R13,R70,R190, } \\
\text { R196,R201 }\end{array}$ & $\begin{array}{l}\text { R16,R70,R108,R } \\
\text { 139,R196,R201 }\end{array}$ & R189 & R195 & R195 \\
\hline $\begin{array}{l}\text { R14,R15,R20,R31,R37,R4 } \\
\text { 4,R50,R55,R61,R94 }\end{array}$ & & & $\begin{array}{l}\text { R31,R55,R61,R } \\
94\end{array}$ & $\begin{array}{l}\text { R15,R20,R31,R3 } \\
7, \text { R55,R61,R94 }\end{array}$ & R20 & $\begin{array}{l}\text { R14,R15,R37, } \\
\text { R44,R50,R61, } \\
\text { R94 }\end{array}$ & $\begin{array}{l}\text { R14,R15,R37, } \\
\text { R44,R50,R61, } \\
\text { R94 }\end{array}$ \\
\hline $\begin{array}{l}\text { R7,R9,R11,R25,R36,R52, } \\
\text { R53,R63,R68,R73,R77,R8 } \\
\text { 4,R88,R100,R104,R107,R } \\
\text { 112,R115,R116,R119,R12 } \\
\text { 4,R135,R141,R152,R179, } \\
\text { R180,R183,R199,R200 }\end{array}$ & & & $\begin{array}{l}\text { R7,R11,R53,R6 } \\
8, \mathrm{R} 73, \mathrm{R} 84, \mathrm{R} 88, \\
\mathrm{R} 112, \mathrm{R} 115, \mathrm{R} 11 \\
\text { 9,R124,R135,R } \\
\text { 179,R180,R199, } \\
\text { R200 }\end{array}$ & $\begin{array}{l}\text { R52,R63,R77,R8 } \\
\text { 8,R104,R107,R1 } \\
\text { 24,R141,R152,R } \\
\text { 179,R183,R199, } \\
\text { R200 }\end{array}$ & $\begin{array}{l}\text { R9,R25,R36,R } \\
\text { 53,R84,R100, } \\
\text { R104,R116,R1 } \\
\text { 52,R183 }\end{array}$ & $\mathrm{R} 100$, & R100, \\
\hline
\end{tabular}

\subsection{The Cycle of Customer Engagement}

Given that social media is based on engagement, analysing studies based on the level of attention to each stage of the customer involvement and engagement cycle can indicate the importance of each of these steps in accepting social commerce. Customer engagement focuses on customer satisfaction by providing higher values for 
competitors in order to build trust and commitment to long-term relationships. The affected customers are considered as the partners who work with vendors in increasing the value in order to better meet their needs, as well as the needs of other customers. In addition, interactive social media greatly facilitates the process of creating sincere, durable relationships through trust and commitment between buyers and sellers. Further, client involvement engages the clients through emotional constraints in their relationship. The process of creating customer involvement is formed by the customer engagement cycle. Furthermore, the idea of the customer engagement cycle is used and referred to as the stages of awareness, attention, research, purchasing, and durability, indicating the stages of the procurement process. Additionally, this process is utilized to help the customers decide on a particular product for the feedback loop regarding their future purchases instead of engaging them, which may have been the first for a new customer to choose which products to buy. The stages of customer engagement include connecting, interacting, satisfying, durability, committing, supporting, and engaging. Figure 5 displays the results of evaluating studies, which were conducted in the field of social commerce acceptance and the focus on each stage of the customer engagement cycle. As shown, the stages of interaction, connectivity, and satisfaction have attracted the most attention in the acceptance of social commerce in the investigation.

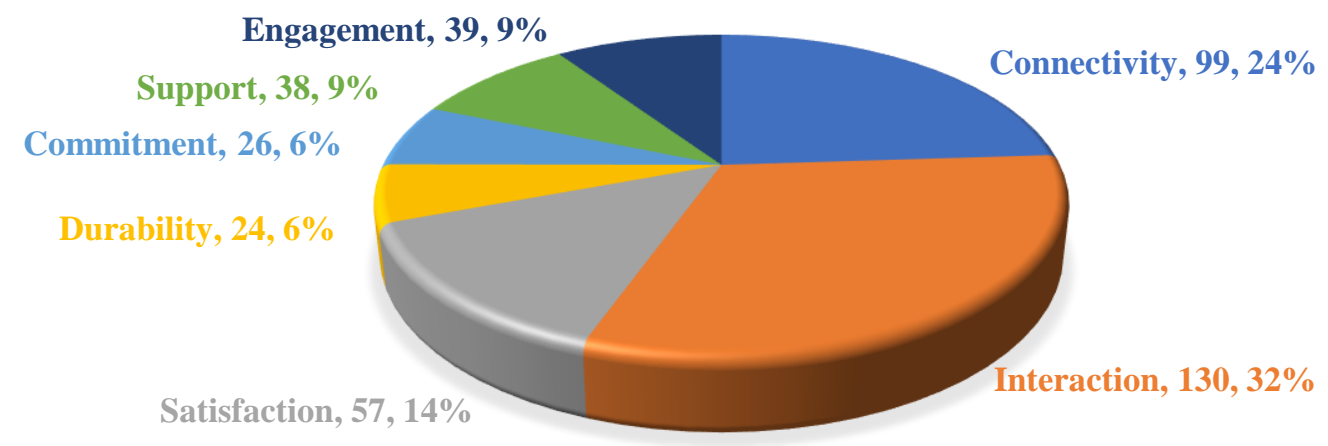

Figure 5. The extent of studies conducted in each of the customer engagement cycles 


\subsection{Applied Area of Study}

Studies have typically focused on one or more functional area(s). The studied areas of research extremely differ and include both the delivery of goods and the provision of services. In addition, some studies have covered both the provision of services and goods. Figure 6 exhibits the amount of attention paid to the study of the acceptance of social commerce to the delivery of goods and the provision of services. It is possible to determine the distribution of studies and precise application areas. Figure 7 depicts what type of application which was emphasized by the study.

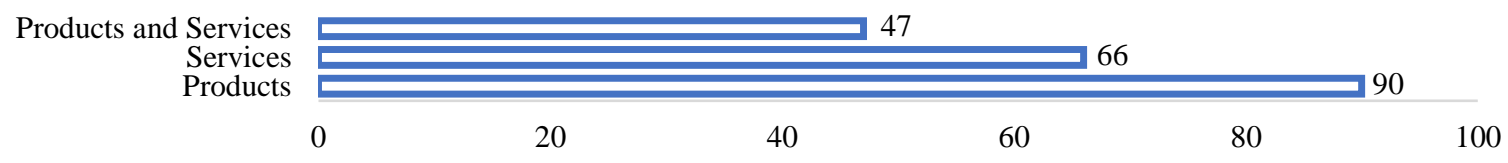

Figure 6. The extent of the focus of studies on product buying or service provision

\subsection{Business Transactions}

The studies of social commerce adoption can be reviewed relying on the transactions in the electronic business. Transactions represent the parties which are involved in the business. Accordingly, studies were reviewed based on their focus on business transactions. Based on the results, B2C, C2C, and B2B transactions acquired the highest attention in the studies. The distribution of the types of studies on transactions is shown in Figure 7.

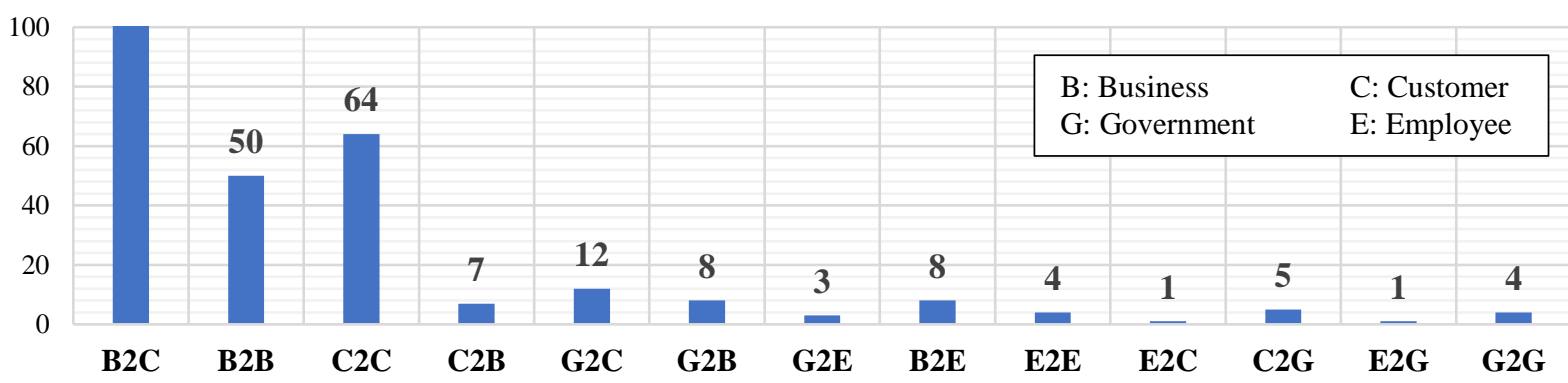

Figure 7. The focus of studies on business transaction types

\subsection{The Geographical Focus of Studies}

Based on the survey, adoption studies are normally conducted at the national level. Considering the evaluated studies and their geographic distribution, determining the countries which have received attention is possible. Figures 8 and 9 illustrate the study rates by country and continent and the studies related to each country, respectively. 


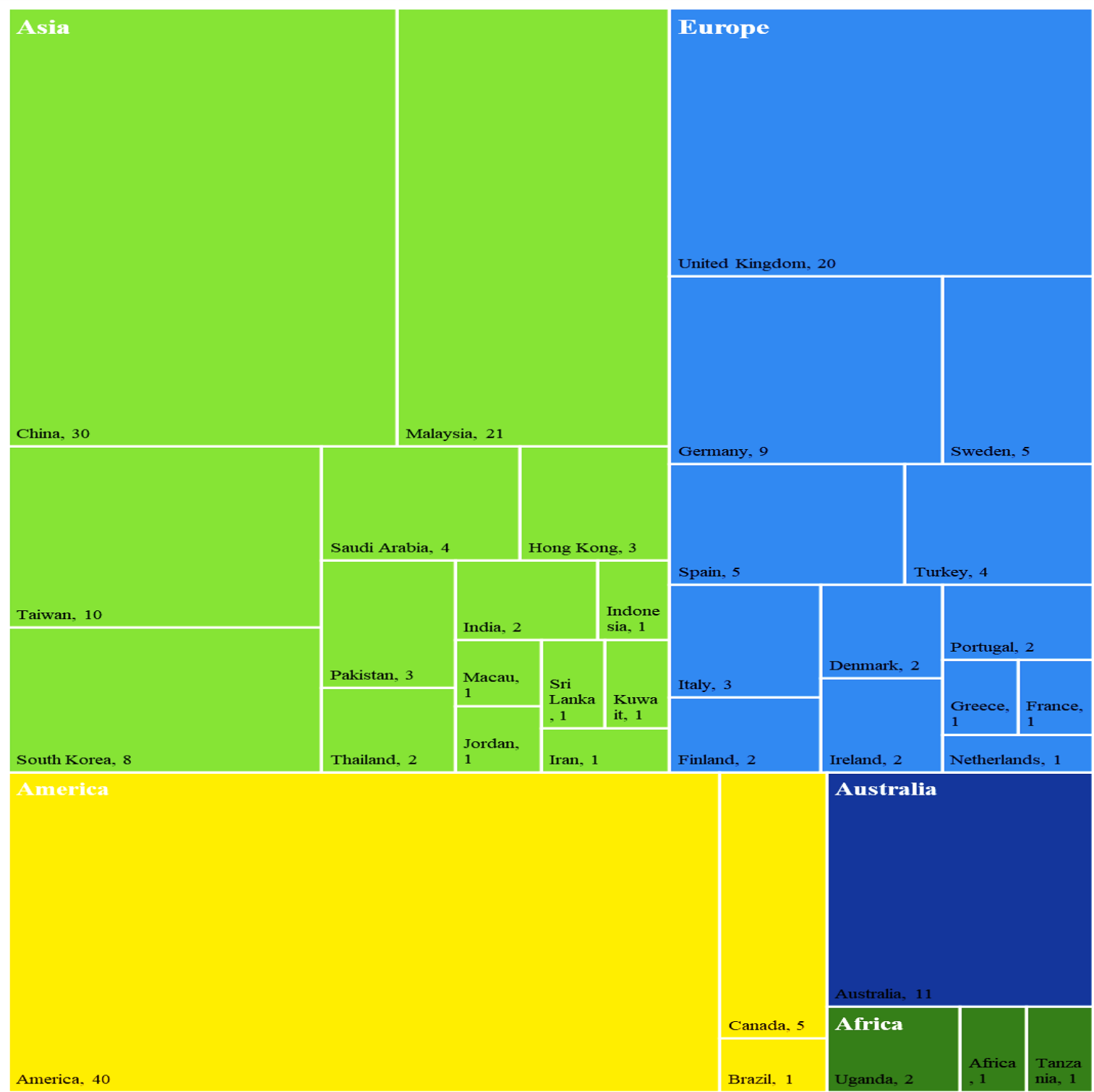

Figure 8. Geographical distribution of social commerce adoption research based on country and continent 


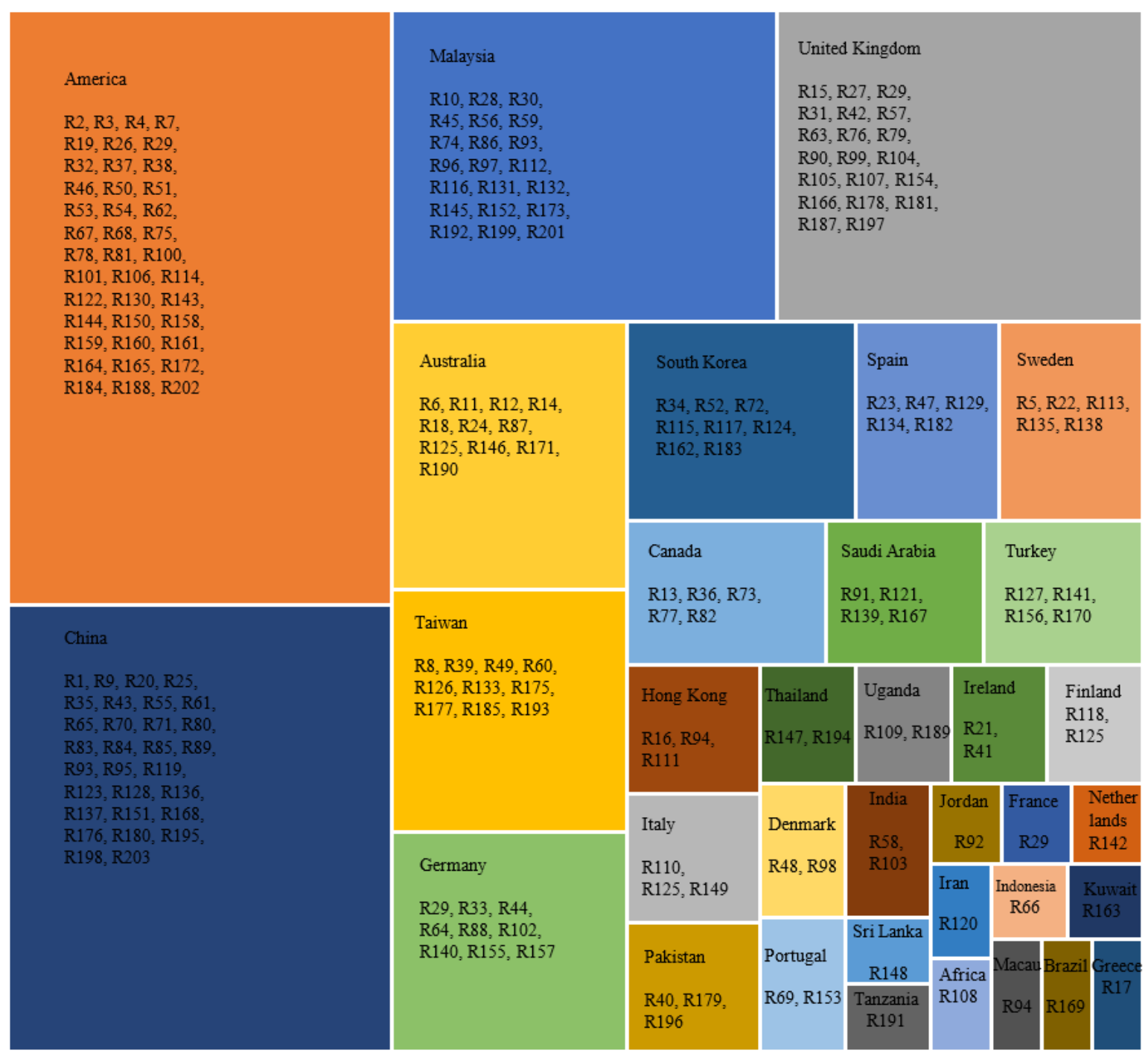

Figure 9. Classification of the studies based on the country

\subsection{Innovation Adoption}

The comparison and classification are based on the technology-organizationenvironment (TOE) framework, which is developed in technology innovation processes by Tornatzky and Fleischer [20]. The TOE framework is considered as an organizationlevel theory, which addresses three different elements influencing organizational decisions. These three elements involve technological, organizational, and environmental contexts. All three cases are confirmed to be effective in technological innovation [20]. Based on this framework, the present review evaluated studies on the acceptance of social commerce and their focus on one of these three areas. Accordingly, $54 \%$ of studies focused on the field of environment and related issues in the field of social commerce acceptance. Technology and technological factors are considered as the second parameter and account for about $29 \%$ of the studies. Finally, organizational variables and factors involve $17 \%$ of all studies.

To determine the context of the studies, the technology context was divided into social media, platforms, electronic business, and information systems, followed by assigning the environmental context to individual, social, and cultural factors. Further, 
organizational context included performance, value chain, readiness, strategy, and business models. Table 5 provides a distribution of studies based on context and subcontexts. The dominant domain in the study was considered to determine the context of the studies. This is because studies related to the admission of social commerce typically cover different fields although the focus of studies and their dominant fields are considered for segmentation.

Table 5. The context of studies based on the TOE framework

\begin{tabular}{|c|c|c|c|c|c|c|c|}
\hline Context & \multicolumn{7}{|l|}{ Sub-contexts } \\
\hline \multirow[t]{2}{*}{ Technology } & \multicolumn{2}{|c|}{ Social Media } & \multicolumn{2}{|c|}{ Platforms } & Ele & ctronic Business & $\begin{array}{c}\text { Information } \\
\text { Systems }\end{array}$ \\
\hline & \multicolumn{2}{|c|}{$\begin{array}{l}\text { R8,R13,R14,R23,R33, } \\
\text { R35,R42,R48,R50,R53 } \\
\text {,R54,R58,R61,R64,R6 } \\
\text { 7,R70,R82,R83,R99,R } \\
\text { 126,R158,R164,R176, } \\
\text { R180 }\end{array}$} & \multicolumn{2}{|c|}{$\begin{array}{l}\text { R15,R18,R19,R25,R2 } \\
\text { 6,R29,R30,R36,R40, } \\
\text { R46,R75,R84,R102,R } \\
\text { 103,R106,R117,R150 } \\
\text {,R155,R156,R157,R1 } \\
\text { 81,R182,R189,R193 }\end{array}$} & $\begin{array}{l}\mathrm{R} 24 \\
25, \mathrm{R} \\
\mathrm{R} 19\end{array}$ & $\begin{array}{l}\text { R38,R45,R66,R1 } \\
\text { 148,R175,R185, } \\
\text { 4,R195 }\end{array}$ & R74 \\
\hline \multirow[t]{2}{*}{ Environment } & \multicolumn{4}{|c|}{ Individual Factors } & & Social Factors & $\begin{array}{l}\text { Cultural } \\
\text { Factors }\end{array}$ \\
\hline & \multicolumn{5}{|c|}{$\begin{array}{l}\text { R1,R4,R5,R10,R12,R16,R17,R20,R22,R27,R28,R34 } \\
\text {,R37,R39,R43,R44,R49,R51,R56,R57,R59,R60,R63, } \\
\text { R65,R68,R69,R71,R77,R78,R80,R85,R86,R87,R88, } \\
\text { R89,R90,R91,R92,R93,R94,R95,R96,R97,R100,R10 } \\
\text { 1,R104,R109,R110,R112,R114,R115,R116,R118,R1 } \\
\text { 19,R120,R121,R122,R123,R124,R127,R129,R132,R } \\
\text { 136,R146,R149,R151,R152,R154,R163,R167,R169, } \\
\text { R170,R171,R172,R174,R178,R191,R192,R199 }\end{array}$} & $\begin{array}{l}\text { R3,R6,R9,R11, } \\
\text { R21,R31,R32,R } \\
\text { 47,R55,R62,R7 } \\
\text { 2,R73,R76,R79, } \\
\text { R105,R107,R11 } \\
\text { 3,R133,R135,R } \\
\text { 145,R168,R173 } \\
\text {,R196 } \\
\end{array}$ & $\begin{array}{l}\text { R81,R138,R16 } \\
\text { 2,R198,R202, } \\
\text { R203 }\end{array}$ \\
\hline \multirow[t]{2}{*}{ Organization } & Performance & \multicolumn{2}{|c|}{ Value Chain } & \multicolumn{2}{|c|}{ Readiness } & Strategy & $\begin{array}{l}\text { Business } \\
\text { Models }\end{array}$ \\
\hline & $\begin{array}{l}\text { R41,R111,R18 } \\
4, R 201\end{array}$ & \multicolumn{2}{|c|}{$\begin{array}{l}\text { R108,R134,R139,R } \\
\text { 144,R161,R165,R1 } \\
\text { 66,R177,R183,R18 } \\
6, \mathrm{R} 188, \mathrm{R} 190, \mathrm{R} 197\end{array}$} & $\begin{array}{l}\text { R7,R130 } \\
\text { R141,R1 } \\
53, \mathrm{R} 179\end{array}$ & $\begin{array}{l}\text { R13 } \\
47, \mathrm{R} \\
\mathrm{R} 200\end{array}$ & R140,R143 & $\begin{array}{l}\text { R2,R52,R98, } \\
\text { R128,R137,R } \\
\text { 142,R159,R1 } \\
87\end{array}$ \\
\hline
\end{tabular}

Note. TOE: Technology-organization-environment.

\subsection{Adoption Phases}

Adoption is regarded as one of the major trends associated with innovation, which focuses on incentive factors or barriers regarding deciding for innovation adoption [21]. Adoption to innovation normally involves a three-stage cycle including pre-adoption, adoption, and post-adoption and a decision to adopt is considered as the output of the pre-adoption stage. Innovation studies are historically technology-driven due to their economic issues and technology management ${ }^{5,6}$. In this regard, the studies are evaluated by focusing on each stage of innovation adoption. Based on the characteristics of each of the adoption steps and their impact on adoption, some keywords can be identified as an indicator at each stage. For example, studies related to the pre-adoption stage normally used keywords such as "the intention to social commerce adoption", buy, word of mouth", and other factors which are required for adoption. Furthermore, the adoption and acceptance stage was characterized by keywords such as "behavioural intention", "intention to participate", "intention to buy, acceptance, and use", and other variables. Additionally, post-adoption studies were identified by keywords such as "satisfaction", "loyalty", "continuity of use", and "continuity of intention". Eventually, the studies which considered some concepts such as branding, knowledge sharing, operational efficiency, and innovation, as well as those related to the institutionalization 
of social commerce are considered as post-adoption studies. Table 6 represents the usage rate of each keyword.

Table 6. Keywords identified for adoption phases

\begin{tabular}{ll}
\hline Phase & Keywords (percent use) \\
\hline Pre-adoption & $\begin{array}{l}\text { Behavioural Intention (26\%), intention to use (16\%), intention to buy (48\%), social } \\
\text { commerce intention (14\%), and word of mouth intention (8\%) }\end{array}$ \\
\hline Adoption & $\begin{array}{l}\text { Use and acceptance (38\%), buy decision (31\%), continues intention (13\%), and other } \\
\text { keywords such as value co-creation, customer perception, customer behaviour, and } \\
\text { the like (18\%) }\end{array}$ \\
\hline Post-adoption & $\begin{array}{l}\text { Satisfaction (19\%), loyalty (24\%), continues behaviour (14\%), continues use (10\%), } \\
\text { and the other keywords such as brand co-creation, knowledge sharing, and the like } \\
(33 \%)\end{array}$ \\
\hline
\end{tabular}

Figure 10 illustrates the distribution of time-dependent studies of each section based on the categorization of studies on the pre-adoption, adoption, and post-adoption stages.

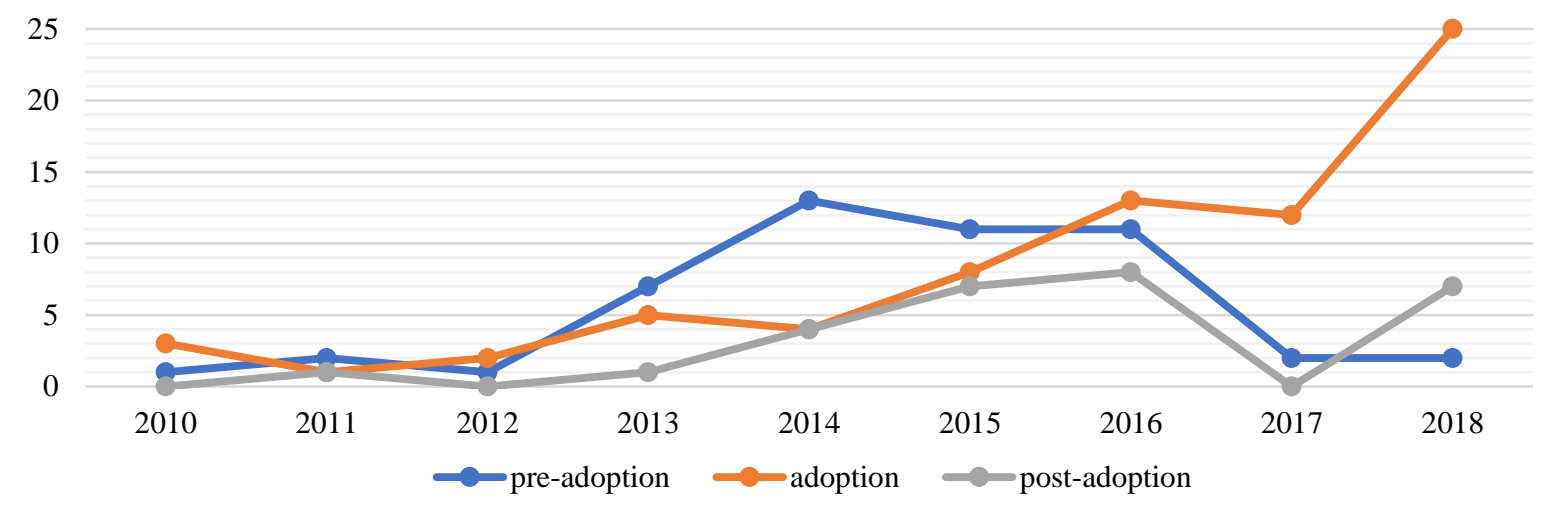

Figure 10. Temporal distribution of social commerce adoption studies based on adoption phases

\subsection{Basic Theory}

The basic theory is discussed as one of the perspectives which can be used to evaluate the studies. The applied theory demonstrates a research orientation. Several theories are used in the study of the acceptance and use of social commerce, which are from different domains including the psychology (e.g., the attribution theory, stimulusorganism-response model, flow theory, and the like), information system (e.g., the model related to information system success and information model), mathematics (e.g., graph, game, and network theory), social science (e.g., social capital theory), and business transaction (e.g., customer value theory) domains, and the like. Figure 17 displays the temporal distribution of theories in the studies and Table 7 presents basic domains and theories based on their usage rate and perspective focus. 


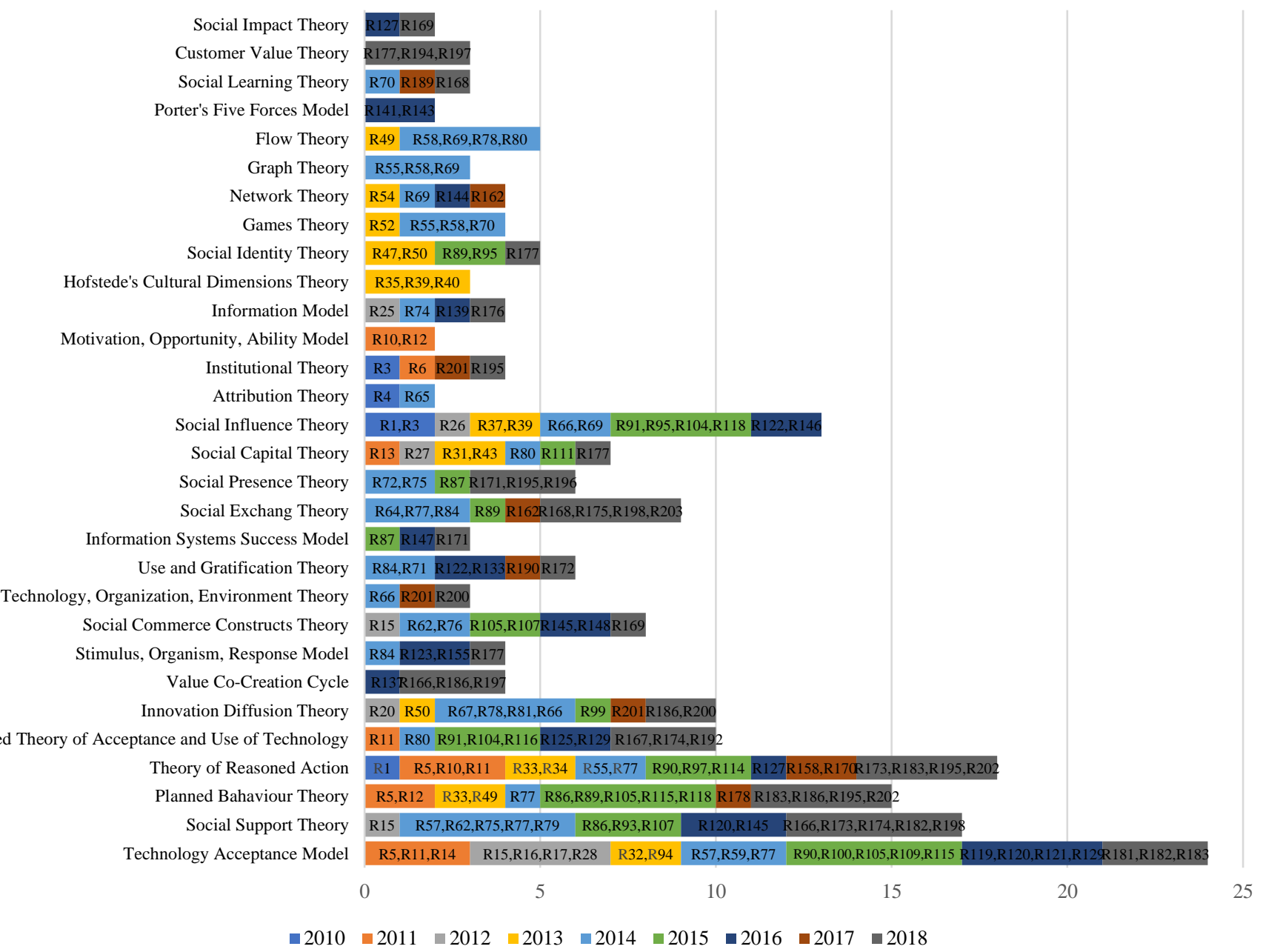

Figure 11. Temporal distribution of social commerce adoption studies based on basic theories 
Table 7. Classification of fundamental theories of social commerce adoption

\begin{tabular}{|c|c|c|c|c|}
\hline $\begin{array}{l}\text { Category of } \\
\text { Theory }\end{array}$ & Theory & Count & Percent & Perspective Focus \\
\hline \multirow{6}{*}{$\begin{array}{l}\text { Technology } \\
\text { Acceptance }\end{array}$} & Technology Acceptance Model & 24 & 8.05 & Customer \\
\hline & Theory of Planned Behaviour & 15 & 5.03 & Customer \\
\hline & Theory of Rational Action & 16 & 5.37 & Customer \\
\hline & Innovation Diffusion Theory & 10 & 3.35 & Customer \\
\hline & Unified Theory of Acceptance and Use of Technology & 6 & 2.01 & Customer \\
\hline & TOE Theory & 2 & 0.67 & Business \\
\hline \multirow[t]{9}{*}{ Social Science } & Social Identity Theory & 5 & 1.67 & Customer-Transaction \\
\hline & Social Capital Theory & 7 & 2.35 & Customer-Transaction \\
\hline & Social Support Theory & 17 & 5.70 & Customer-Transaction \\
\hline & Social Influence Theory & 11 & 3.69 & Customer-Transaction \\
\hline & Social Presence Theory & 6 & 2.01 & Customer-Transaction \\
\hline & Social Impact Theory & 2 & 0.67 & Customer-Transaction \\
\hline & Social Cognitive Theory & 2 & 0.67 & Customer-Transaction \\
\hline & Social Learning Theory & 3 & 1.00 & Customer-Transaction \\
\hline & Social Exchange Theory & 9 & 3.02 & Customer-Transaction \\
\hline \multirow[t]{2}{*}{$\begin{array}{l}\text { Information } \\
\text { Science }\end{array}$} & Information Model & 4 & 1.34 & $\begin{array}{c}\text { Customer-Business- } \\
\text { Transaction }\end{array}$ \\
\hline & Information System Success Model & 3 & 1.00 & $\begin{array}{c}\text { Customer-Business- } \\
\text { Transaction }\end{array}$ \\
\hline \multirow[t]{3}{*}{ Mathematics } & Graph Theory & 3 & 1.00 & Transaction \\
\hline & Network Theory & 4 & 1.34 & Transaction \\
\hline & Game Theory & 4 & 1.34 & Transaction \\
\hline \multirow[t]{7}{*}{ Psychology } & Flow Theory & 5 & 1.67 & Customer \\
\hline & MOA Model & 2 & 0.67 & Customer-Business \\
\hline & Expectancy Theory & 6 & 2.01 & Customer \\
\hline & Use and Gratification Theory & 7 & 2.35 & Customer \\
\hline & S-O-R Model & 4 & 1.34 & Customer \\
\hline & Trust Transfer Theory & 4 & 1.34 & Customer \\
\hline & Attribution Theory & 2 & 0.67 & Customer \\
\hline \multirow[t]{3}{*}{ Value Chain } & Value Co-Creation Cycle & 5 & 1.67 & $\begin{array}{c}\text { Customer-Business- } \\
\text { Transaction } \\
\end{array}$ \\
\hline & Customer Value Theory & 3 & 1.00 & $\begin{array}{c}\text { Customer-Business- } \\
\text { Transaction }\end{array}$ \\
\hline & Social Commerce Constructs & 6 & 2.01 & Customer-Transaction \\
\hline \multirow{3}{*}{$\begin{array}{l}\text { Organizationa } \\
\text { 1 Science }\end{array}$} & Institutional Theory & 4 & 1.34 & Business \\
\hline & Porter's Competitive Forces Model & 2 & 0.67 & Business \\
\hline & Hofstede Cultural Model & 4 & 1.34 & Customer-Business \\
\hline
\end{tabular}


Table 7. Classification of fundamental theories of social commerce adoption

\begin{tabular}{|c|c|c|c|c|}
\hline $\begin{array}{l}\text { Category of } \\
\text { Theory }\end{array}$ & Theory & Count & Percent & Perspective Focus \\
\hline Other & 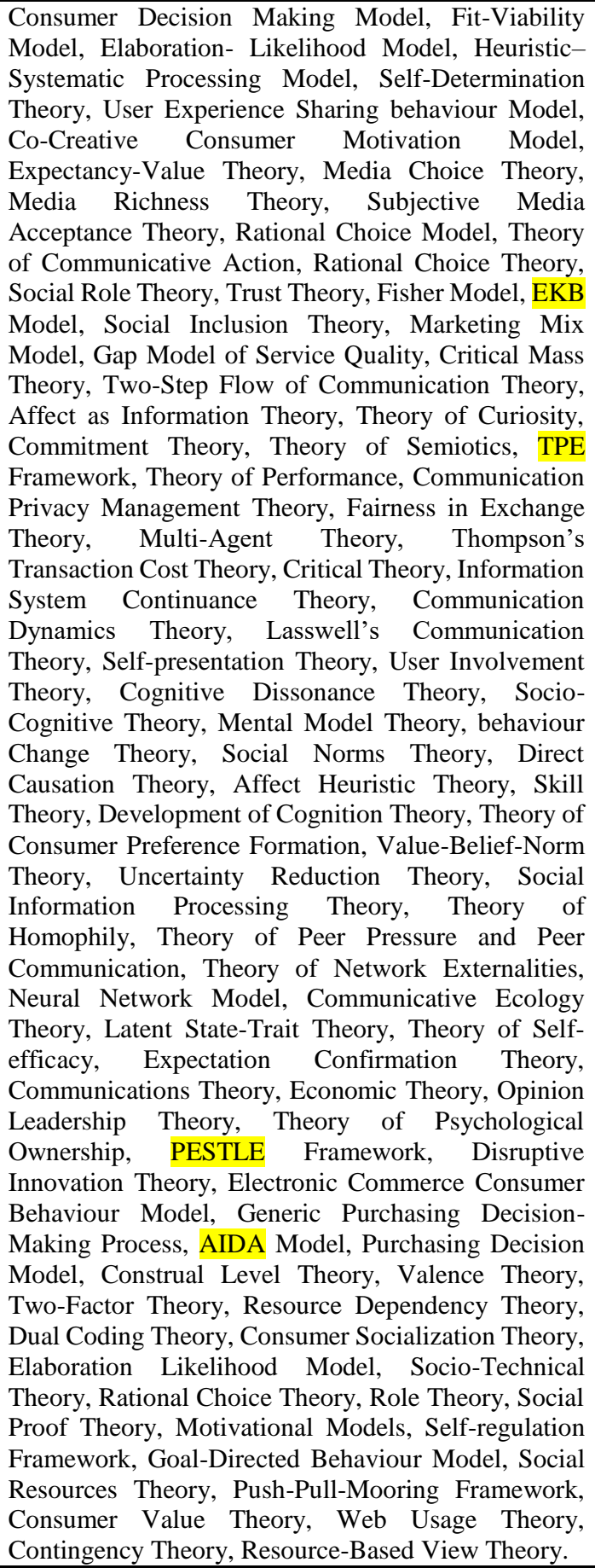 & 1 & 30.53 & $\begin{array}{l}\text { Customer-Business- } \\
\text { Transaction }\end{array}$ \\
\hline
\end{tabular}

\subsection{Innovation Space}

The innovation space was introduced by Badilescu in order to evaluate the distance between knowledge created by the introduction of innovation and to reduce and bridge the knowledge gap. This method includes informational, cognitive, and social spaces [22]. Ford considers cognitive space as a dark space [23]. In addition, cognitive space 
is somehow related to the skills of the individuals. Considering the social space, the smallest social structure, which plays a dominant role in accepting innovation, is considered as a community of practice and is characterized by a close relationship between its members. Further, this community is of great importance for the first stage of the acceptance of the innovator regarding creating new methods of action. Furthermore, this social structure is critical for the diffusion of innovation since its members are the first to represent innovation application and discover how to overcome the initial problems. The members of this community are professionals who know each other and frequently meet face to face [24]. Information space like the social space uses practical and cognitive skills to acquire information. Additionally, queries, analyses, assessments of information needs, and the decisions are affected by the actual skills and information retrieved from both sources.

It is worth noting that some studies have addressed more than one area of innovation. In addition, the trend of using innovative spaces in the context of the acceptance of social commerce represents that primary studies have focused more on the cognitive space of innovation acceptance and sought to identify the individual characteristics, perceptions, and skills which led to the acceptance of social commerce. In the following section, the tendency toward information space is observed in the study (e.g., focusing on media types, their features, media attraction factors, and the like). Further, recent studies have highlighted the social dimensions of acceptance in social commerce, which are considered as the third wave of studies.

Attention to the considered factors in the studies is regarded as one of the applicable approaches for evaluating the innovation space in social entrepreneurship acceptance studies. Accordingly, the main influencing factors in all social commerce acceptance studies were identified and listed in terms of their application and area of influence. Each of these factors can represent a focus on an innovation space. Table 8 presents the concerned innovation space identified for each factor and the focus of each factor on each of the aspects of TOE theory.

Table 8. Influencing factors in social commerce acceptance studies

\begin{tabular}{|c|c|c|c|c|c|}
\hline Factor & Count & Percent & Area of Influence & $\begin{array}{c}\text { Adoption } \\
\text { Space }\end{array}$ & TOE Focus \\
\hline Trust & 69 & 6.51 & User behaviour & Cognitive & Environment \\
\hline Perceived ease of use & 37 & 3.49 & User perception & Cognitive & Environment \\
\hline Perceived usefulness & 48 & 4.53 & User perception & Cognitive & Environment \\
\hline Emotional support & 8 & 0.75 & User behaviour & Cognitive & Environment \\
\hline Informational support & 9 & 0.84 & User behaviour & Informational & Environment \\
\hline Attitude & 31 & 2.93 & User perception & Cognitive & Environment \\
\hline Subjective norms & 7 & 0.66 & User perception & Cognitive & Environment \\
\hline Perceived behavioural control & 7 & 0.66 & User perception & Cognitive & Environment \\
\hline Beliefs & 3 & 0.28 & User perception & Cognitive & Environment \\
\hline Expected performance & 6 & 0.56 & User perception & Cognitive & Environment \\
\hline Expected effort & 6 & 0.56 & User perception & Cognitive & Environment \\
\hline Social influence & 17 & 1.60 & User behaviour & Social & Environment \\
\hline Facilitating conditions & 5 & 0.47 & Transaction status & Informational & Technology \\
\hline Network structure & 6 & 0.56 & $\begin{array}{l}\text { Transaction } \\
\text { infrastructure }\end{array}$ & Social & Technology \\
\hline Position in the network & 3 & 0.28 & User status & Social & Technology \\
\hline $\begin{array}{l}\text { Amount of centrality in the } \\
\text { network }\end{array}$ & 4 & 0.38 & User status & Social & Technology \\
\hline Control & 10 & 0.94 & User behaviour & Cognitive & Environment \\
\hline Intention to socialize & 10 & 0.94 & User behaviour & Cognitive & Environment \\
\hline Mutual understanding & 4 & 0.38 & User perception & Social & Environment \\
\hline Visibility & 4 & 0.38 & Transaction conditions & Informational & Technology \\
\hline Customer engagement & 7 & 0.66 & User behaviour & Social & Environment \\
\hline
\end{tabular}


Table 8. Influencing factors in social commerce acceptance studies

\begin{tabular}{|c|c|c|c|c|c|}
\hline Factor & Count & Percent & Area of Influence & $\begin{array}{l}\text { Adoption } \\
\text { Space } \\
\end{array}$ & TOE Focus \\
\hline Stimulus & 4 & 0.38 & Transaction status & Cognitive & Environment \\
\hline Virtual communities & 4 & 0.38 & $\begin{array}{l}\text { Transaction } \\
\text { infrastructure }\end{array}$ & Social & Environment \\
\hline Shared hopes and aspirations & 4 & 0.38 & User perception & Social & Environment \\
\hline Technology & 10 & 0.94 & Transaction conditions & Informational & Technology \\
\hline Perceived benefits & 7 & 0.66 & User perception & Cognitive & Environment \\
\hline Social structure & 3 & 0.28 & Transaction conditions & Social & Environment \\
\hline Compatibility & 6 & 0.56 & Business behaviour & Cognitive & Organization \\
\hline Ability & 4 & 0.38 & User behaviour & Cognitive & Environment \\
\hline Organization and community & 22 & 2.07 & Business behaviour & Social & Organization \\
\hline Information & 66 & 6.23 & $\begin{array}{l}\text { Transaction } \\
\text { infrastructure }\end{array}$ & Informational & Technology \\
\hline $\begin{array}{l}\text { Tolerance of ambiguity and } \\
\text { uncertainty }\end{array}$ & 2 & 0.19 & User behaviour & Informational & Environment \\
\hline Value of relationships & 43 & 4.06 & Transaction conditions & Social & Environment \\
\hline Field of activities & 3 & 0.28 & Transaction conditions & Cognitive & Environment \\
\hline Buyers power & 16 & 1.51 & Business situation & Informational & Organization \\
\hline Value of pleasure & 4 & 0.38 & User perception & Cognitive & Environment \\
\hline $\begin{array}{l}\text { Number of sources of work } \\
\text { applied }\end{array}$ & 5 & 0.47 & Transaction conditions & Cognitive & Environment \\
\hline Motivation of pleasure & 6 & 0.56 & User perception & Cognitive & Environment \\
\hline Habit & 2 & 0.19 & User behaviour & Cognitive & Environment \\
\hline Comparative advantage & 5 & 0.47 & Business behaviour & Cognitive & Organization \\
\hline Trialability & 2 & 0.19 & Business behaviour & Cognitive & Organization \\
\hline Organization & 9 & 0.85 & Business situation & Social & Organization \\
\hline Environment & 5 & 0.47 & Business situation/E & Social & Environment \\
\hline Motivation & 12 & 1.13 & User perception & Cognitive & Environment \\
\hline Needs & 9 & 0.85 & User perception & Cognitive & Environment \\
\hline Gratifications & 30 & 2.83 & User perception & Cognitive & Environment \\
\hline Expectations & 18 & 1.70 & User perception & Cognitive & Environment \\
\hline Information quality & 13 & 1.23 & $\begin{array}{l}\text { Transaction } \\
\text { infrastructure }\end{array}$ & Informational & Technology \\
\hline System quality & 4 & 0.38 & $\begin{array}{l}\text { Transaction } \\
\text { infrastructure }\end{array}$ & Informational & Technology \\
\hline Service quality & 10 & 0.94 & $\begin{array}{l}\text { Transaction } \\
\text { infrastructure }\end{array}$ & Informational & Technology \\
\hline Intrinsic interest & 7 & 0.66 & User perception & Cognitive & Environment \\
\hline Group knowledge acquisition & 9 & 0.85 & User behaviour & Social & Environment \\
\hline Amount of network connections & 7 & 0.66 & Transaction status & Social & Technology \\
\hline Attention & 4 & 0.38 & User behaviour & Cognitive & Environment \\
\hline Group knowledge sharing & 9 & 0.85 & User behaviour & Social & Technology \\
\hline Compatibility and adaptability & 6 & 0.56 & Business behaviour & Cognitive & Organization \\
\hline Complexity & 4 & 0.38 & Transaction conditions & Cognitive & Organization \\
\hline Structural bridging & 3 & 0.28 & User behaviour & Social & Environment \\
\hline Organism & 4 & 0.38 & Transaction status & Cognitive & Environment \\
\hline Forums & 3 & 0.28 & $\begin{array}{l}\text { Transaction } \\
\text { infrastructure }\end{array}$ & Social & Environment \\
\hline Ratings & 5 & 0.47 & User behaviour & Informational & Technology \\
\hline Interaction & 25 & 2.36 & User behaviour & Social & Environment \\
\hline Social presence & 12 & 1.13 & User behaviour & Social & Environment \\
\hline Recommendations & 6 & 0.56 & User behaviour & Informational & Technology \\
\hline Identification & 13 & 1.28 & User perception & Cognitive & Environment \\
\hline Peoples & 7 & 0.66 & User status & Social & Environment \\
\hline Position in the social network & 2 & 0.19 & User status & Social & Technology \\
\hline Collectivism & 3 & 0.28 & User perception & Cognitive & Environment \\
\hline Network relationships & 2 & 0.19 & Transaction conditions & Social & Environment \\
\hline Value of activities & 2 & 0.19 & Transaction conditions & Cognitive & Environment \\
\hline Power of suppliers & 4 & 0.38 & Business situation & Informational & Organization \\
\hline Functional value & 2 & 0.19 & User perception & Cognitive & Environment \\
\hline Social value & 4 & 0.38 & User perception & Social & Environment \\
\hline
\end{tabular}


Table 8. Influencing factors in social commerce acceptance studies (Cont.)

\begin{tabular}{|c|c|c|c|c|c|}
\hline Factor & Count & Percent & Area of Influence & $\begin{array}{l}\text { Adoption } \\
\text { Space }\end{array}$ & TOE Focus \\
\hline User satisfaction & 26 & 2.45 & User behaviour & Cognitive & Environment \\
\hline Reciprocity & 3 & 0.28 & User behaviour & Social & Environment \\
\hline Reputation and credibility & 12 & 1.13 & User perception & Cognitive & Environment \\
\hline Industry environment & 7 & 0.66 & Business situation & Informational & Environment \\
\hline $\begin{array}{l}\text { Environment-organization } \\
\text { relationships }\end{array}$ & 1 & 0.09 & Business behaviour & Informational & Environment \\
\hline Competitive value & 6 & 0.56 & Business situation & Informational & Environment \\
\hline Power & 10 & 0.94 & Business situation & Cognitive & Environment \\
\hline Competitive market & 2 & 0.19 & Business situation & Informational & Organization \\
\hline Normative expectations & 12 & 1.13 & Business behaviour & Cognitive & Environment \\
\hline Opportunity & 3 & 0.28 & Transaction conditions & Informational & Environment \\
\hline Imagine yourself & 2 & 0.19 & User perception & Cognitive & Environment \\
\hline Self-esteem & 1 & 0.09 & User perception & Cognitive & Environment \\
\hline Social identity & 8 & 0.75 & User perception & Social & Environment \\
\hline Socialization skill & 42 & 3.96 & User behaviour & Cognitive & Environment \\
\hline Socialization knowledge & 35 & 3.30 & User behaviour & Cognitive & Environment \\
\hline $\begin{array}{l}\text { Internal determination against } \\
\text { external reward }\end{array}$ & 3 & 0.28 & User perception & Cognitive & Environment \\
\hline Curiosity & 3 & 0.28 & User behaviour & Informational & Environment \\
\hline Common goals & 5 & 0.47 & User perception & Social & Environment \\
\hline Social commerce platform & 2 & 0.19 & $\begin{array}{l}\text { Transaction } \\
\text { infrastructure }\end{array}$ & Social & Technology \\
\hline $\begin{array}{l}\text { Opportunity to exchange ideas } \\
\text { and benefits }\end{array}$ & 12 & 1.13 & Transaction conditions & Informational & Environment \\
\hline Value co-creation & 9 & 0.85 & User behaviour & Social & Technology \\
\hline Response & 4 & 0.38 & User behaviour & Informational & Environment \\
\hline Reviews & 10 & 0.94 & User behaviour & Informational & Technology \\
\hline Social ties & 19 & 1.79 & User behaviour & Social & Environment \\
\hline Obligation & 10 & 0.94 & User behaviour & Cognitive & Environment \\
\hline Social interaction & 6 & 0.56 & User behaviour & Social & Environment \\
\hline Resource control & 4 & 0.38 & Business behaviour & Informational & Technology \\
\hline Internalization & 2 & 0.19 & User perception & Cognitive & Environment \\
\hline Referrals & 4 & 0.38 & User behaviour & Informational & Technology \\
\hline Organizational resources & 1 & 0.09 & Business situation & Informational & Organization \\
\hline Individualism & 3 & 0.28 & User perception & Cognitive & Environment \\
\hline Network activities & 3 & 0.28 & Transaction conditions & Social & Technology \\
\hline Field of relations & 5 & 0.47 & Transaction conditions & Social & Environment \\
\hline $\begin{array}{l}\text { Threats of alternative goods or } \\
\text { services }\end{array}$ & 3 & 0.28 & Business situation & Informational & Organization \\
\hline Source power of the work & 4 & 0.38 & Business situation & Informational & Organization \\
\hline Monetary and financial value & 5 & 0.47 & User perception & Cognitive & Environment \\
\hline
\end{tabular}

Note. TOE: Technology-organization-environment.

\subsection{The Types of Research Methods Used in Studies}

Based on the classification charts shown in Figure 18, the studies are divided into experimental and non-experimental categories, each of which has some sub-categories. Based on these categories, the type of applied research method in the study of social commerce was evaluated and classified into three levels by considering the number of studies. 


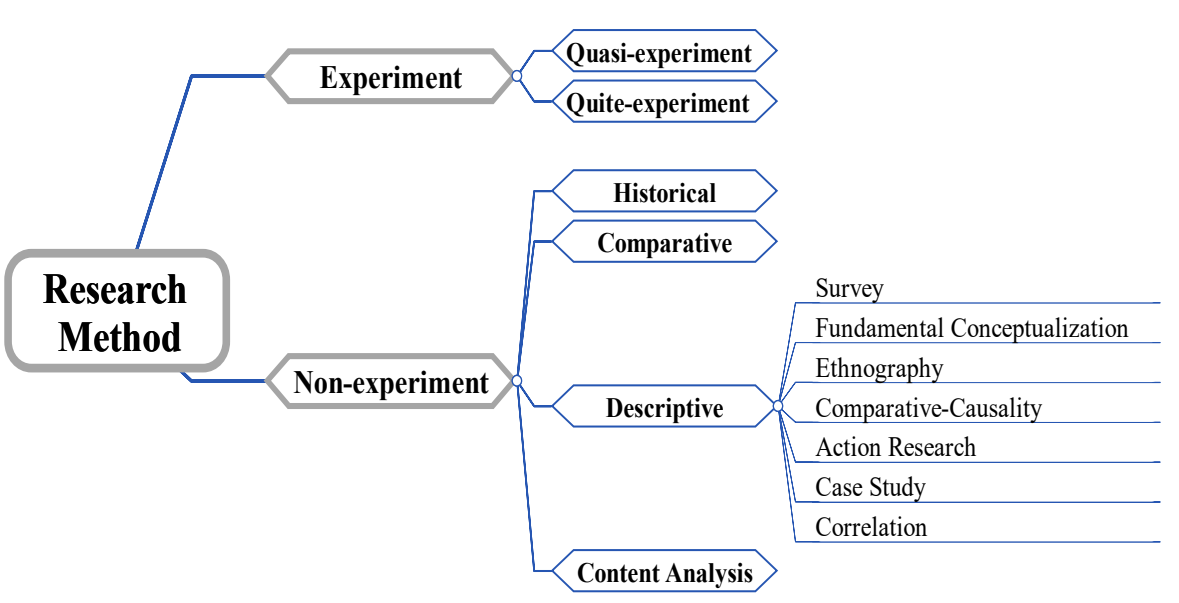

Figure 12. Research method classification for evaluating social commerce adoption studies

Figures 13 and 14 display the first level results with a high percentage of nonexperiment methods, as well as the higher contribution of descriptive research on the second level, respectively. As shown in Figure 15, the survey is the most used method in the third level.

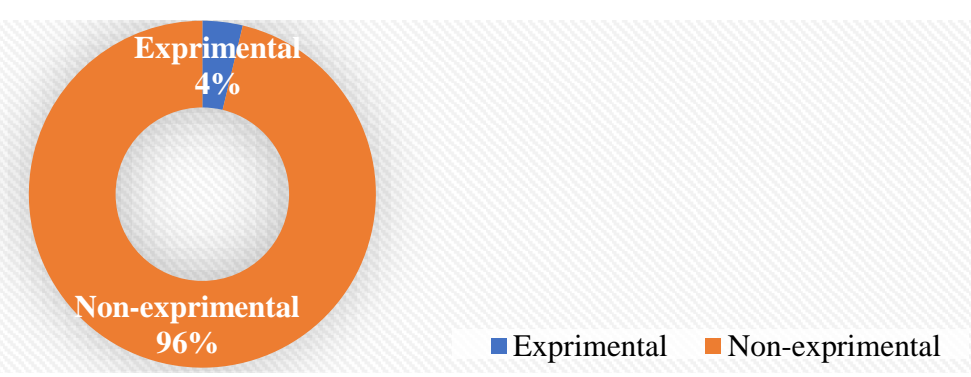

Figure 13. The analysis of studies based on the first level research method classification

To review the applied methods accurately, Figure 16 depicts the extent of the use of applied methods based on time and method distribution.

-Quasi-experimental
-Quite-experimental
$\square$ Historical
Content Analysis
Descriptive
-Comparative

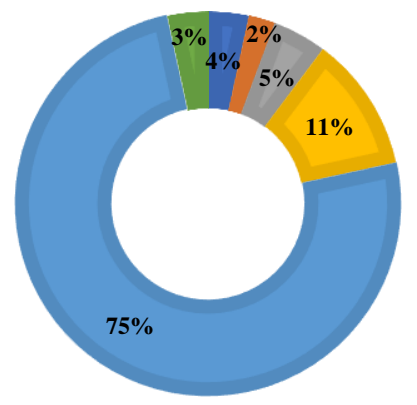

Figure 14. The analysis of studies based on the second level research method classification 

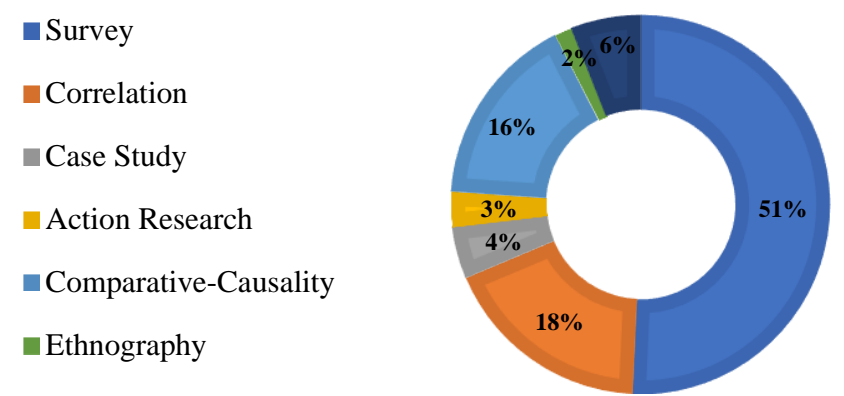

Figure 15. The analysis of studies based on the third level research method classification

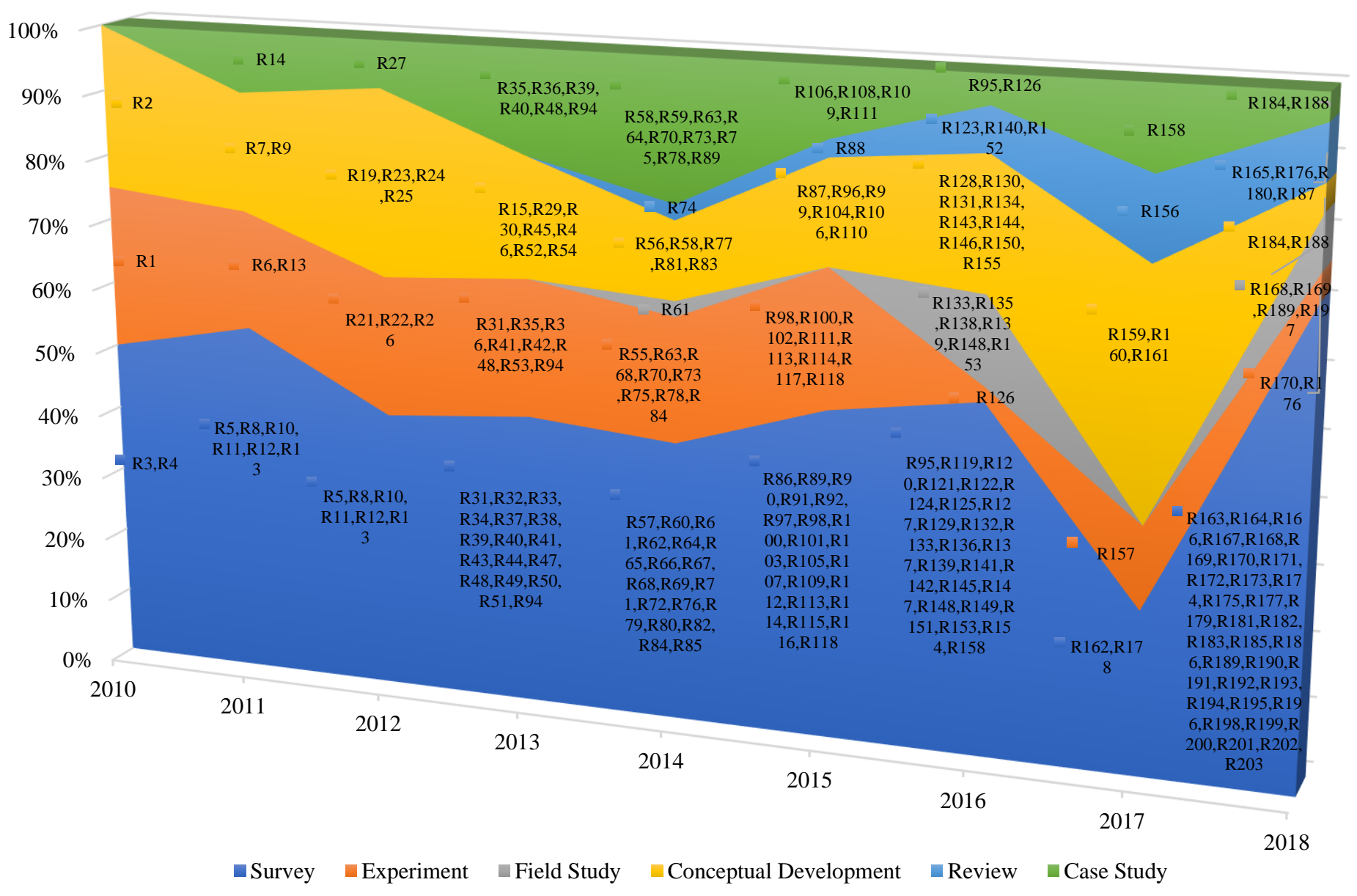

Figure 16. Temporal distribution of social commerce adoption research based on research methods

\subsection{Research References}

Various sources have published social commerce adoption studies. Some of these resources were discussed in the present study. In this regard, journal paper, conference paper, academic thesis, and book chapters were evaluated based on the strategies followed in the present study regarding selecting research resources. Figure 17 illustrates the temporal distribution of the results of different references. 


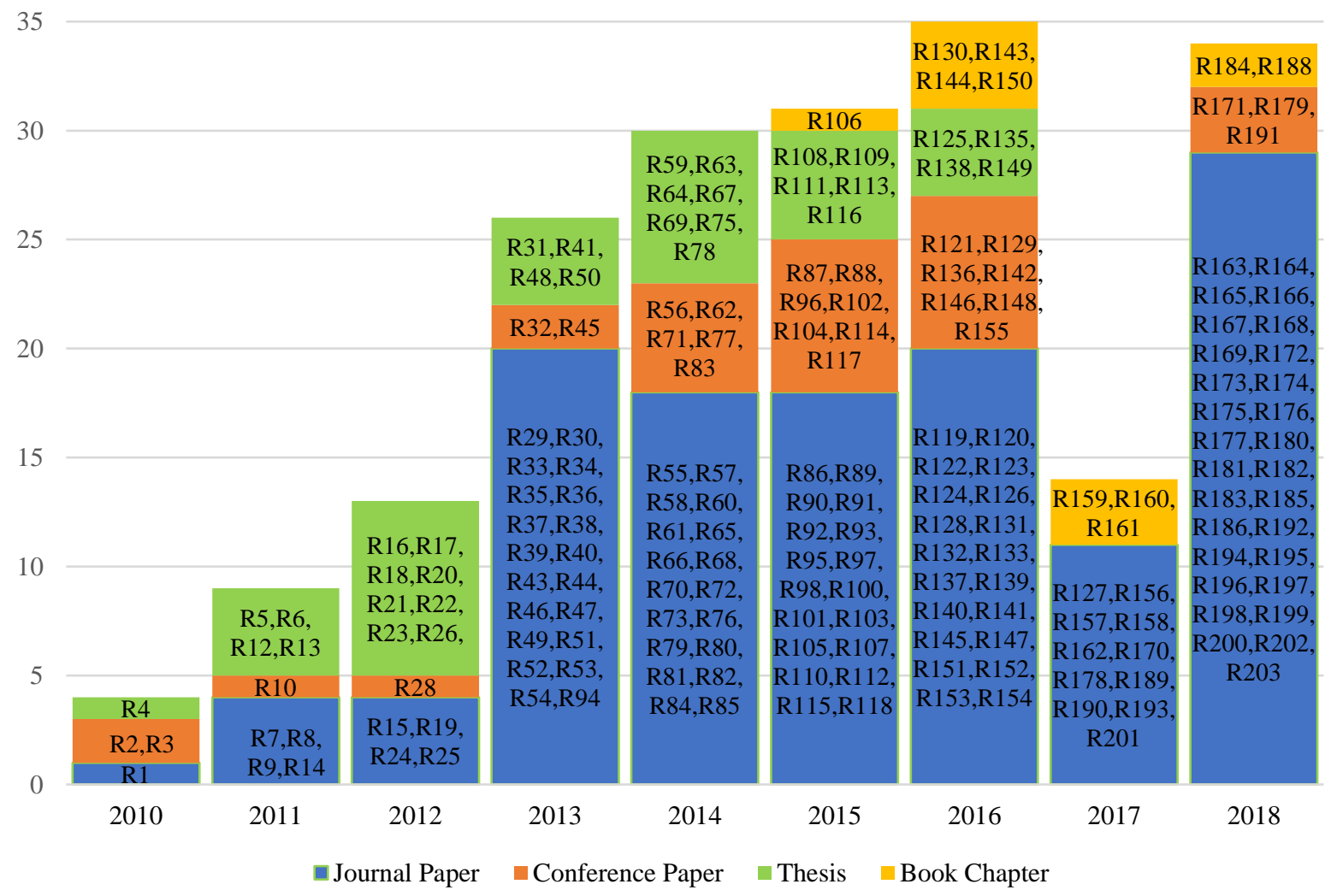

Figure 17. Temporal distribution of studies based on resource types

The focus of various journals regarding the publication of studies related to the acceptance of social commerce is shown in Figure 18 and Table 9. 
Table 9. The rate of study publication on social commerce acceptance in different journals

\begin{tabular}{|c|c|c|c|}
\hline Journal & $\begin{array}{l}\text { Count } \\
\text { of Use }\end{array}$ & Journal & $\begin{array}{l}\text { Count } \\
\text { of Use }\end{array}$ \\
\hline $\begin{array}{lll}\text { Electronic Commerce } & \text { Research and } \\
\text { Applications } & & \\
\end{array}$ & 11 & Electronic Commerce in Organizations & 1 \\
\hline Information and Management & 8 & Internet and e-Business Studies & 1 \\
\hline Information Management & 7 & $\begin{array}{l}\text { Communications of the Association for Information } \\
\text { Systems }\end{array}$ & 1 \\
\hline $\begin{array}{l}\text { Organizational Computing and Electronic } \\
\text { Commerce }\end{array}$ & 5 & Human Resource Management Research & 1 \\
\hline Electronic Commerce & 4 & Information Technology & 1 \\
\hline Electronic Commerce Research & 4 & Management Science & 1 \\
\hline Computers in Human Behaviour & 4 & DeReMa Journal Manajemen & 1 \\
\hline $\begin{array}{llll}\begin{array}{l}\text { Technological } \\
\text { Change }\end{array} & \text { Forecasting and Social } \\
\end{array}$ & 4 & Telematics and Informatics & 1 \\
\hline Interactive Marketing & 3 & $\begin{array}{l}\text { and e-Service, along with Science and } \\
\text { Technology }\end{array}$ & 1 \\
\hline Information Technology and People & 3 & Indian Culture and Business Management & 1 \\
\hline International Marketing & 3 & Information Development & 1 \\
\hline Management Information Systems & 3 & Industrial and Business Management & 1 \\
\hline Internet Research & 3 & Transactions on Internet and Information Systems & 1 \\
\hline Commerce and Social Sciences & 2 & Management Research & 1 \\
\hline Electron Markets & 2 & Hospitality and Tourism Research & 1 \\
\hline Information Sciences & 2 & Services Marketing & 1 \\
\hline Market Research & 2 & Electronic Business & 1 \\
\hline Decision Support Systems & 2 & Internet Commerce & 1 \\
\hline Business Research & 2 & Business Perspectives and Research & 1 \\
\hline $\begin{array}{lll}\begin{array}{l}\text { Electronic } \\
\text { Management }\end{array} & \text { Customer } & \text { Relationship } \\
\end{array}$ & 1 & Global Economics & 1 \\
\hline Computer Science & 1 & Advanced Science Letters & 1 \\
\hline $\begin{array}{l}\text { Cyber psychology, Behaviour, and Social } \\
\text { Networking }\end{array}$ & 1 & Digital Convergence & 1 \\
\hline Intercultural Communication Studies & 1 & Enterprise Information Systems & 1 \\
\hline Information and Software Technology & 1 & Data Analysis and Information Processing & 1 \\
\hline Customer Behaviour & 1 & Modern Applied Science & 1 \\
\hline Asia-Pacific Business & 1 & Science and Technology & 1 \\
\hline Kybernetes & 1 & Marketing Theory and Practice & 1 \\
\hline Internet Marketing and Advertising & 1 & Entrepreneurship in Emerging Economies & 1 \\
\hline MIS Quarterly & 1 & Human-Computer Interaction & 1 \\
\hline $\begin{array}{l}\text { Communication Networks and Distributed } \\
\text { Systems }\end{array}$ & 1 & Information Management and Computer Security & 1 \\
\hline Retailing and Consumer Services & 1 & Development Studies & 1 \\
\hline
\end{tabular}




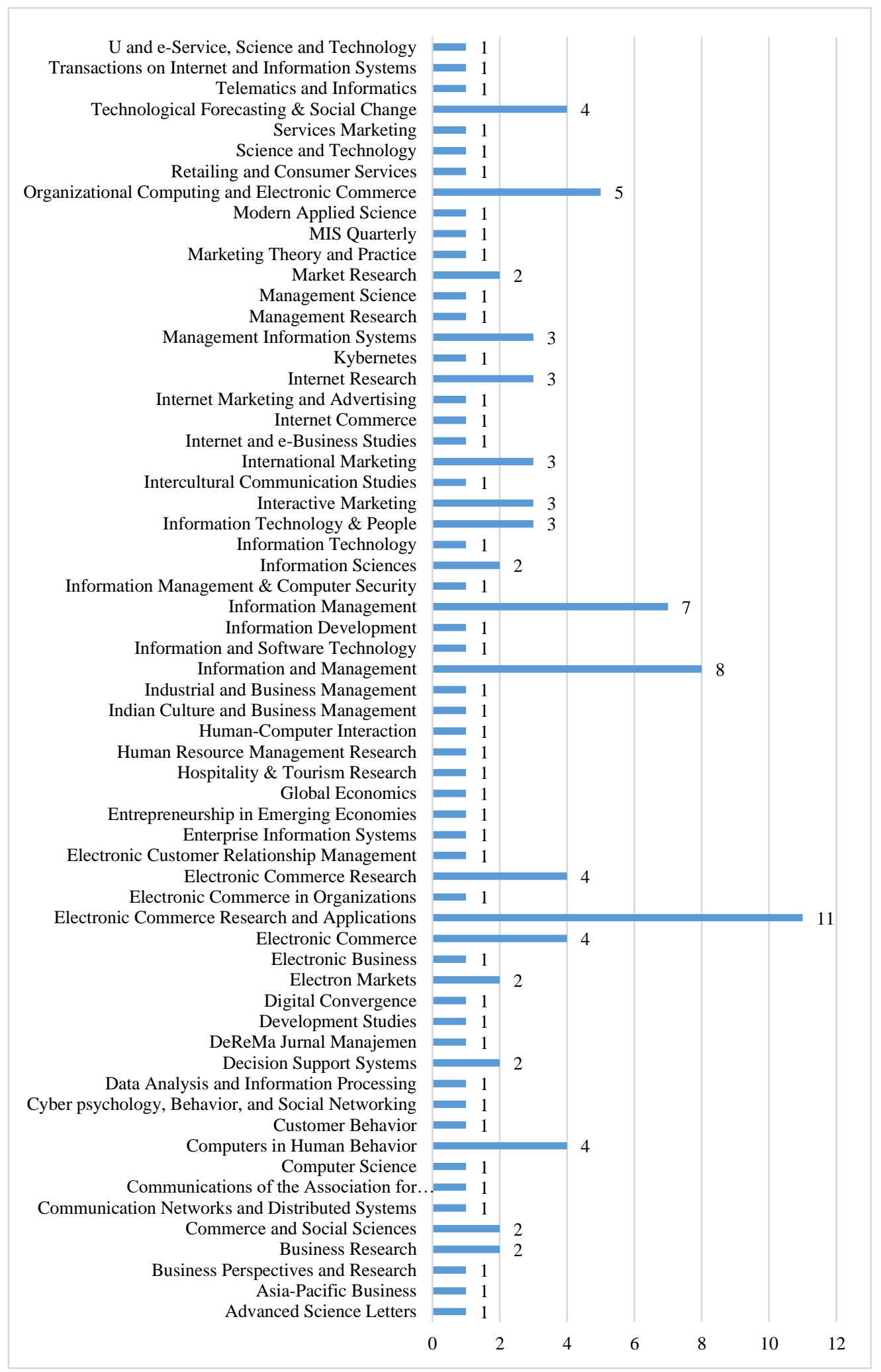

Note. MIS: Management Information Systems.

Figure 18. Comparing the publication of social commerce adoption studies in various journals 


\subsection{Research Output}

The research outputs were reviewed to identify the types of research results. Figure 19 displays the research output mind map.

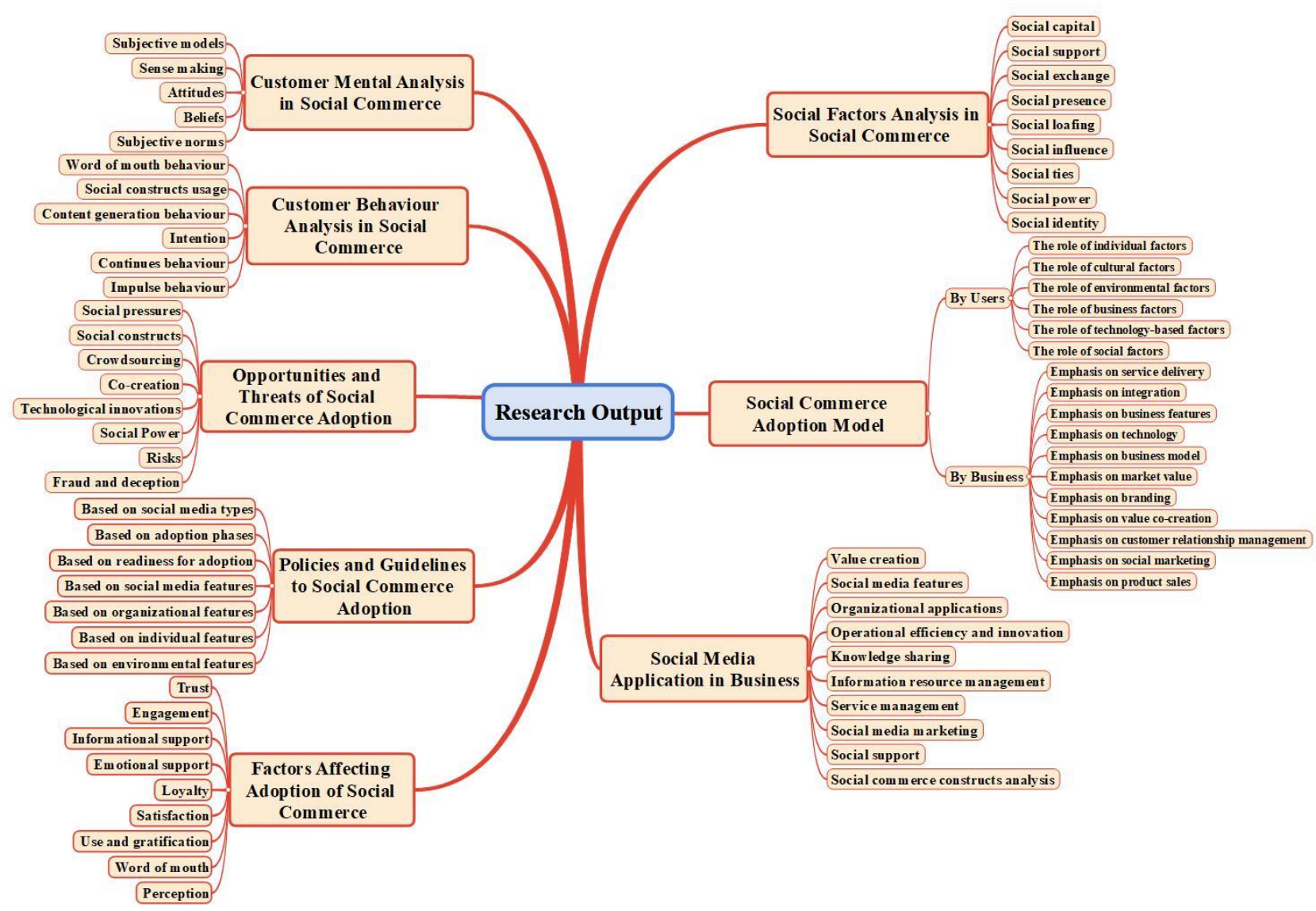

Figure 19. Mind Map of Research Output

\section{CONCLUSIONS}

Social commerce as a new paradigm in the field of commerce has experienced various trends from different perspectives over the short period of its life. More precisely, over the past decade, three evolutionary periods have been highlighted in social commerce acceptance studies. The first generation was related to studies in which the applied platform was considered as the social media that hosted business processes and relied on social media. A prime example is the Facebook social network which has the most studies, followed by the Twitter microblog. This generation of short-lived studies focused on business-to-customer transactions, especially the cognitive environment of innovation acceptance. Furthermore, these studies addressed user behaviour and the pre-acceptance stages of social commerce since they sought to find users who were attracted to social commerce. Value mechanisms relied solely on communication between the users and business activities were nearly exclusively marketed in this space. In the customer engagement cycle, their focus was on connecting the customer to the social space of the business and most studies were conducted using the surveys. The output of studies in this generation typically focused on identifying factors influencing customers' willingness to embrace social commerce, especially those business activities which sought to sell the product. The basic applied theories in the studies of 
this generation were mainly theories of technology adoption such as the technology acceptance model, the theory of planned behaviour, and the theory of rational action. Additionally, factors used as the determinants of social commerce acceptance were individual factors which focused on the social commerce customer.

In addition, a new approach to social commerce was gradually considered in the second generation of social commerce acceptance studies, with businesses moving to an ecommerce platform toward using social structures in business. Companies such as Amazon, Groupon, Coupang, Wal-Mart, and eBay were included in these studies. Such companies used a second approach to e-commerce, in which business processes were considered as the core infrastructure and social structures were added to the infrastructure as well. In this generation, more diverse business transactions were considered, including business-to-customer and customer-to-customer transactions, as well as business-to-customer transactions which were significant in all three generations. Further, innovation acceptance studies that have now passed the preacceptance phase have focused on the innovation acceptance stage. At this stage, the acceptance of social commerce by businesses was considered in addition to paying attention to the customers, as well as the outputs of studies and the customer behaviour on business behaviour with components such as marketing, branding, teamwork, customer engagement, customer relationship management, and the like. This generation of studies addressed the delivery of services over social commerce and in some areas of services such as entertainment, education, and tourism. Furthermore, these studies focused on the information space of innovation in the field of social commerce in addition to the cognitive space and considered information enrichment, along with easy and inexpensive access to information on social media as one of the key components of acceptance. Additionally, studies were used in this generation of experimental, conceptual, and contextual studies and case studies in addition to surveying methods. Further, mathematical theories such as graph, network, and game theories were increasingly used in studies and particular attention was paid to social theories, especially social support and social influence theories. Furthermore, such studies typically provided the models of acceptance by customers and businesses and some studies sought to present policies, challenges, threats, and opportunities as well. Unlike the previous generation of studies which focused on individual factors such as perceived ease of use, perceived usefulness, attitude, this generation of studies emphasized interpersonal factors and relationships such as perceived trust, satisfaction, perceived privacy, experience, reputation, perceived value, and the like. Geographic focus unlike the first generation of studies focusing on countries such as China, the United Kingdom, and the United States, geographic diversity of studies has developed and different countries such as Germany, Australia, South Korea, Malaysia, Canada, Sweden, and Spain was added to the field of active countries in the social commerce development and studies.

Additionally, the third generation of social commerce studies, as a mature generation, focused on the stages of acceptance and after acceptance of social commerce by customers and businesses. This generation even pushed businesses which had a strong focus on the business process to social commerce. Studies of companies such as Fashion Bag, Yelp, Best Bay, House of Fashion, Hellodc, Meilishuo, and the like demonstrate a second approach to social commerce for businesses that have attempted to add social media instruments to their business processes. In this generation, a variety of business transactions were studied in the context of social commerce such as business transactions with employees and even with the government. It should be noted that 
some state-owned businesses are joining the process and some third-generation studies focus on government transactions with customers, employees, and businesses in the context of social commerce platforms. In addition, government transactions are observed in the third generation, reflecting the analysis and risk-taking of state-owned companies in joining new trends in technology. In this generation, social media services such as product sales have received special attention. The focus on businesses and the adoption of social commerce are becoming more pronounced and even more attention is given to business models, service delivery, entrepreneurship, crowdsourcing, and crowdfunding although in limited studies. Further, customers are still the focus in this generation of studies and this time special attention is paid to social factors such as social presence, social capital, and social loafing although studies in this field are extremely rare. The two new added areas to the focus of studies are the focus of system studies and media studies. Factors such as system, platform, content, and service quality are evaluated in this area. The variety of theories used as the basic theories in this generation increases since theories such as attribution theory, information system success model, stimulus, organism, response model, institutional theory, Porter competitive forces model, Hofstede cultural model, social learning theory, expectation theory, customer value theory, and the like are concerned with different areas such as psychology, social psychology, information systems, organizational behaviour, and the like. Unlike the previous two generations, which emphasized the two stages of connectivity and interaction in the customer engagement cycle, studies of this generation focused on the stages of satisfaction, durability, commitment, support, and engagement. Furthermore, third-generation studies are looking at the value creation of networking, complementing, and combining methods which are considered as the main potentials of social media. The variety of studied media in this generation is enormous. Unlike the other two generations, with a major focus on social networks and microblogs, this generation addressed a variety of media including video sharing, image sharing, social messenger, group shopping sites, blogs, and social games, online communities, social services sites, and social shopping sites in addition to social networks and microblogs. Interesting transactions in the cognitive space of innovation from interpersonal transactions in the second generation became social transactions extensively based on the social space of innovation. The use of social factors in studies indicates this issue. Eventually, the methods of field studies and reviews are significant in this generation, as well as the method of surveying which has a special place in the studies of all three generations.

\section{IMPLICATIONS}

Several trends are evident in the studies concerning the business audience approach. Previous studies further addressed the first social commerce approach focusing on social media platforms (e.g., Facebook, LinkedIn, and Twitter) instead of the business processes platform-based approach with social constructs. In terms of the applied social media in studies, social networks and microblogs ranked the highest. Considering the three distinct areas of user or customer, business, and transaction as the three entities of social commerce, most studies focus on the user or customer and fall into the next category of transaction and business role issues have the least amount of studies. Additionally, the mechanisms of value creation through social commerce focus on the stages of collaboration and communication. In the customer engagement cycle, two stages of interaction and connectivity have the greatest potential for engagement in social commerce. In addition, most studies on the acceptance of social commerce 
focused on the provision of goods. Among the business transactions, the business transaction with the customer (B2C) received the most attention. Geographically, continental, Asian, and country-by-country, the United States has the largest number of studies on social commerce acceptance. Concerning the researcher's audience approach, several noteworthy trends emerged from the reviews. Most outputs of acceptance studies emphasized presenting an acceptance model which focuses on the role of the customer and the user. Journal articles addressed social commerce acceptance more than any other source. Further, trust was considered as one of the most important components which was used as an influencing variable on social commerce acceptance. Regarding research methods, surveying was one of the most widely used methods in all the studied years. Among the basic theories, the technology acceptance model, social support theory, reasoned action theory, and planned behaviour theory were the most widely applied theories. Among the acceptance stages, most studies, especially in recent years, have addressed the adoption stage. Finally, the cognitive space was considered as the innovation space in most studies.

\section{FUTURE STUDIES}

Based on observable trends in the resource review of business-oriented and researchbased approaches, the following recommendations were provided based on the existing research gaps.

1. Focusing on the second approach of social commerce based on the business process platform with social structures;

2. Addressing service delivery in social commerce acceptance studies;

3. Highlighting different types of social media, a wide variety of which were studied in small quantities;

4. Emphasizing the use of empirical methods in studies;

5. Concentrating on content analysis, historical, and comparative methods for the analysis;

6. Focusing on various business-like transactions;

7. Using cross-cultural study methods for higher coverage and generalizability;

8. Addressing the organizational domain in studies on the acceptance of social commerce as an innovation;

9. Applying social variables as independent variables in presenting social commerce acceptance models;

10. Conducting a thematic and content review of the basic theories used in the studies.

\section{CITATIONS}

[1] R. T. Wigand, R. I. Benjamin, and J. L. H. Birkland, "Web 2. 0 and beyond: Implications for electronic commerce," 10th Int. Conf. on Electronic Commerce (ICEC), Innsbruck, Austria, August 2008.

[2] A. M. Kaplan, and M. Haenlein, "Users of the world, unite! The challenges and opportunities of social media," Business Horizons, vol. 53, pp. 59-68, 2010.

[3] G. Dennison, S. Bourdage-Braun, and D. Chetuparambil, "Social commerce defined," IBM Corporation, 2011. 
[4] E. Constantinides, and S. J. Fountain, "Web 2.0: Conceptual Foundations and Marketing Issues". Direct Data and Digital Marketing Practice, vol. 9, pp. 231244, 2008.

[5] T. A. Allan, and M. L. Sosa, "50 years of engineering management through the lens of the IEEE Transactions," IEEE Transactions on Engineering Management, vol. 51, pp. 391-395, 2004.

[6] F. Damanpour, "Footnotes to research on management innovation," Organization Studies, vol. 39, pp. 1265-1285, 2014.

[7] EBSE, "Guidelines for performing systematic literature reviews in software engineering," EBSE Technical Report, Software Engineering Group, School of Computer Science and Mathematics, Keele University, Department of Computer Science, University of Durham, 2007.

[8] M. Bano, and D. Zowghi, "A systematic review of the relationship between user involvement and system success," Information and Software Technology, vol. 58, pp. 148-169, 2015.

[9] N. Qureshi, N. Ikram, M. Bano, and M. Usman, "Empirical evidence in software architecture: a systematic literature review protocol," The Sixth International Conference on Software Engineering Advances (ICSEA), pp. 534-548, 2011.

[10] Z. Huang, and M. Benyoucef, "From e-commerce to social commerce: A close look at design features," Electronic Commerce Research and Applications, vol.12, pp. 246-259, 2013.

[11] S. Abed, Y. Dwivedi, and M. Williams, "Social Media as a Bridge to E-commerce Adoption in SMEs: A Systematic Literature Review," The Marketing Review, vol.15, pp.39-57, 2015.

[12] T. Friedrich, "Analysing the factors affecting consumers' adoption of social commerce-a literature review," Twenty-first Americas Conference on Information Systems, Puerto Rico, 2015.

[13] H. Abdelsalam, A. Busalim, and C. H. Razak, "Understanding social commerce: A systematic literature review and suggestions for further research," International Journal of Information Management, vol.36, pp.1075-1088, 2016.

[14] K. Z .K . Zhang, and M. Benyoucef, "Consumer behaviour in social commerce: A literature review," Decision Support Systems, vol. 86, pp. 95-108, June 2016.

[15] Y. Cui, J. Mou, and Y. Liu, "Knowledge mapping of social commerce research: a visual analysis using CiteSpace," Electronic Commerce Research, vol.18, pp. 837868, 2018.

[16] T. Dyba, T. Dingsoyr, and G. K. Hanssen, "Applying systematic review to diverse study types: an experience report," First International Symposium on Empirical Software Engineering and Measurement (ESEM 2007), Madrid, pp.225-234, Sept. 2007.

[17] D.S. Cruzes, and T. Dyba, "Research synthesis in software engineering: a tertiary study," Inf. Softw. Technol. vol. 53, pp.440-455, 2011.

[18] S. Ketonen-Oksi, J. J. Jussila, and H. Kärkkäinen, "Social media -based value creation and business models," Industrial Management and Data Systems Journal, vol. 116, pp.1820-1838, 2016.

[19] V. Vuori, and J. Jussila, "The 5C categorization of social media tools," $20^{\text {th }}$ International Conference, Tampere, Finland, pp. 26-33, October 2016.

[20] J. Baker, "The technology-organization-environment framework, in Information systems theory: explaining and predicting our digital society,". New York: Springer, vol. 28, pp. 231-246, 2012. 
[21] A. Hecker, and A. Ganter, "The influence of product market competition on technological and management innovation: Firm-level evidence from a large scale survey," European Management Review, vol. 10, pp. 17-33, 2013.

[22] E. Badilescu-Buga, "Knowledge behaviour and social adoption of innovation," Information Processing and Management, vol. 49, pp. 902-911, 2013.

[23] N. Ford, "Modelling cognitive processes in information seeking: From Popper to Pask," Journal of the American Society for Information Science and Technology, vol. 55, pp. 769-782, July 2004.

[24] D. Hung, and M. Nichani, "Differentiating between Communities of Practices (CoPs) and Quasi-Communities: can CoPs exist online?," International Journal on E-Learning, vol.1, pp. 23-29, 2002.

\section{Appendix A. Systematic Literature Review References}

R1. X-L. Shen, M. K. O. Lee, C. MK. Cheung, and H. Chen, "Gender differences in intentional social action: we-intention to engage in social network-facilitated team collaboration," Journal of Information Technology, vol. 25, pp.152-169, 2010.

R2. E. Turban, N. Bolloju, and T-P. Liang, "Social Commerce: An E-Commerce Perspective," ICEC'10, August 2-4, 2010, Honolulu, Hawaii, USA, pp. 33-42, 2010.

R3. A. J. Setterstrom, and J. M. Pearson, "Social Influence and Willingness to Pay for Online Video Games," ICIS Saint Louis, Missouri, USA, December 12-15, 2010 Proceedings. Paper 53, 2010.

R4. M. K. Kim, "The Effectiveness of Product Conversations in Social Media: From an Attribution Theory Perspective," Ph.D. Thesis, Michigan State University, 2010.

R5. A. Loh, "A Study on Influence of Trust, Social identity, Perceived Risk and EWOM on Consumer Decision-Making Process in the context of Social Network Sites," Master Thesis, Blekinge Tekniska Hogskola, School of Management, 2011.

R6. K. S. McKenzie, "An exploration of technical, social and macro societal pressures influencing the adoption of online social networking services by organizations," Ph.D. Thesis, QUT School of Business, 2011.

R7. E. Turban, N. Bolloju, and T-P. Liang, "Enterprise Social Networking: Opportunities, Adoption, and Risk Mitigation," Journal of Organizational Computing and Electronic Commerce, vol. 21, pp. 202-220, July 2011.

R8. L-Y. Pan, and J-S. Chiou, "How Much Can You Trust Online Information? Cues for Perceived Trustworthiness of Consumer-generated Online Information," Journal of Interactive Marketing, vol. 25, pp. 67-74, May 2011.

R9. T-L. Liang, and E. Turban, "Introduction to the Special Issue Social Commerce: A Research Framework for Social Commerce," International Journal of Electronic Commerce, vol.16, pp. 5-13, December 2011.

R10. P-L. Teh, and P. K. Ahmed, "MOA and TRA in Social Commerce: An Integrated Model," IEEE IEEM 2011, December 2011.

R11. M. Talukder, and A. Quazi, "The Impact of Social Influence on Individuals' Adoption of Innovation," Journal of Organizational Computing and Electronic Commerce, vol. 21, pp. 111-135, 2011.

R12. C-H. Tong Chen, "The Rise of Co-Creative Consumers: User Experience Sharing Behaviour in Online Communities," Ph.D. Thesis, Queensland University of Technology, 2011. 
R13. S.H. Lee, "The Structural Importance of Consumer Networks," Ph.D. Thesis, The University of Western Ontario, 2011.

R14. J. Chang, and C. Lewis, "Towards A Framework for Web 2.0 Community Success: A Case of YouTube," Journal of Electronic Commerce in Organizations, vol. 9, pp. 1-14, 2011.

R15. N. Hajli, "A research framework for social commerce adoption," Information Management \& Computer Security, vol. 21, pp. 144-154, July 2013.

R16. J. K. Ayeh, "Analysing the Factors Affecting Online Travellers' Attitude and Intention to Use Consumer-Generated Media for Travel Planning," Ph.D. Thesis, The Hong Kong Polytechnic University, 2012.

R17. G. Tsakonas, "Consumer Behaviour and Group Buying Sites," Master Thesis, Oikonomikon Kai Koinonikon University, Greece, 2012.

R18. M. WJ. Chua, "Diffusion of Travel Information through Innovation: A Social Network Analysis," Bachelor Thesis, School of Tourism, The University of Queensland, 2012.

R19. T-P. Liang, and E. Turban, "Introduction to the Special Issue Social Commerce: A Research Framework for Social Commerce," International Journal of Electronic Commerce, vol. 16, pp. 5-13, 2012.

R20. Y. Liu, "Knowledge, Persuasion, and Decision: Examining the Predictors of Microblogging's Diffusion in China," Ph.D. Thesis, University of Miami, 2012.

R21. L. Griffin, "Managing the Formation and Interaction of Groups within Emerging Social Networks," Ph.D. Thesis, Waterford Institute of Technology, 2012.

R22. A. Petrova, and C. Valles, "Perceived risks as adoption barriers of Facebook commerce: Exploring Facebook users' perceptions," Master Thesis, Jonkoping International Business School, 2012.

R23. L. Braun, "Social Media and Public Opinion, " Master Thesis, Valencia University, 2012.

R24. O. Sohaib, and K. Kang, "The Effect of Technology, Human and Social Networks in Serviceable Cross-Culture Business-to-Consumer (B2C) Websites," Journal of Internet and e-Business Studies, vol. 10, pp. 1-11, January 2012.

R25. C. Wang, and P. Zhang, "The Evolution of Social Commerce: The People, Management, Technology, and Information Dimensions," Journal of Communications of the Association for Information Systems, vol. 31, pp. 105127, Novamber 2012.

R26. K. H. Lee, "The Influences of the Just-in-time Social Cloud on Real World Decisions, " Ph.D. Thesis, Massachusetts Institute of Technology, 2012.

R27. D. Padua, "Trust, Social Relations and Engagement Understanding Customer Behaviour on the Web," Palgrave Macmillan publication, 2012.

R28. P-L. Teh, and P.K. Ahmed, "Understanding Social Commerce Adoption: An Extension of the Technology Acceptance Model," $6^{\text {th }}$ International Conference on Management of Innovation and Technology, ICMIT2012, June 2012.

R29. M.S. Yadva, K. De Valck, T. Hennig-Thurau, D.L. Hoffman, and M. Spann, "Social Commerce: A Contingency Framework for Assessing Marketing Potential," Journal of Interactive Marketing, vol. 27, pp. 311-323, 2013.

R30. T. Y. Jing, and H. Al-Samarraie, "A Review towards the Use of Social Networking Sites (SNSs) as E-commerce Platform," Human Resource Management Research, vol. 3, pp. 188-193, 2013.

R31. A. Razzaque, "Assessing the Impact of Physicians' Social Capital on Decision Making Quality Mediated by Knowledge Sharing in a Virtual Community of 
Practice: an Empirical Quantitative Analysis," Ph.D. Thesis, Brunel University, 2013.

R32. X. Lin, Y. Li, C. B. Califf, and M. Featherman, "Can Social Role Theory Explain Gender Differences in Facebook Usage?" 46th Hawaii International Conference on System Sciences, Wailea, Maui, pp. 690-699, January 2013

R33. B. W. Wirtz, R. Piehler, and S. Ullrich, "Determinants of Social Media Website Attractiveness," Journal of Electronic Commerce Research, vol. 14, pp. 11-33, 2013.

R34. S. Kim, and H. Park, "Effects of Various Characteristics of Social Commerce on Consumers 'Trust and Trust Performance," International Journal of Information Management, vol. 33, pp. 318-332, 2013.

R35. M. Lin, "Electronic Word-of-Mouth on Microblogs: A Cross-cultural Content Analysis of Twitter and Weibo," Intercultural Communication Studies, vol. 22, pp. 18-42, December 2013

R36. Z. Huang, and M. Benyoucef, "From e-commerce to social commerce: A close look at design features," Electronic Commerce Research and Applications, vol. 12, pp. 246-259, 2013.

R37. A. Bilgihan, C. Peng, and J. Kandampully, "Generation Y's dining information seeking and sharing behaviour on social networking sites," International Journal of Contemporary Hospitality Management, vol. 26, pp. 349-366, 2014.

R38. J-Y. M. Kang, and K.P. Johnson Kim, "How does social commerce work for apparel shopping? Apparel social e-shopping with social network storefronts," Journal of Customer Behaviour, vol. 12, pp. 53-72, 2013.

R39. C. S-P. Ng, "Intention to Purchase on Social Commerce Websites across Cultures: A Cross-regional Study," Information \& Management Journal, vol. 50, pp. 609620, December 2013.

R40. A. Talat, S. Azar, and M. W. Yousaf, "Investigating Social Commerce as an Alternate Model for Online Commerce in Developing Countries: a case of Pakistani Economy," Pakistan Journal of Commerce and Social Sciences, vol. 7, pp. 223-242, 2013.

R41. C. Devenney, "Investigating the power of social media in enhancing the brand reputation of SME's," Master Thesis, Department of Business, School of Business, Letterkenny Institute of Technology, 2013.

R42. F. Nel, and O. Westlund, "Managing New(s) Conversations: The Role of Social Media in News Provision and Participation," Handbook of Social Media Management, Media Business and Innovation, 2013.

R43. H. Yang, "Market Mavens in Social Media: Examining Young Chinese Consumers' Viral Marketing Attitude, eWOM Motive, and Behaviour," Journal of Asia-Pacific Business, vol. 14, pp. 154-178, 2013.

R44. A. S. Güngör, and T. O. Çadirci, "Segmenting EWOM Engager on Online Social Networks Based on Personal Characteristics and Behaviour," Ekev Academic Review, vol. 17, pp. 33-47, September 2013

R45. C. S. Ling, and W. Husain, "Social Commerce in E-Business: Challenges and Guidelines for Successful Adoption," International Conference on Advanced Computer Science and Information Systems, ICACSIS 2013, Kuta - Bali, pp. 1730, September 2013.

R46. L. Zhou, P. Zhang, and H-D. Zimmermann, "Social commerce research: An integrated view," Electronic Commerce Research and Applications, vol. 12, pp. 61-68, 2013. 
R47. J. Arenas-Gaitan, F-J. Rondan-Cataluna, and P.E. Ramı 'rez-Correa, "Social identity, electronic word-of-mouth, and referrals in social network services," Kybernetes, vol. 42, pp. 1149-1165, 2013.

R48. L. J. Lopez, "Social Media as a way to enhance Customer Service," Master Thesis, Copenhagen Business School, 2013.

R49. I-C. Chang, C-C. Liu, and K. Chen, "The effects of hedonic/utilitarian expectations and social influence on continuance intention to play online games," Internet Research, vol. 24, pp. 21-45, 2013.

R50. C. A. Lawry, "The Role of Parasocial Interaction and Social Media Participation in the Two-Step Flow of Communication", Ph.D. Thesis, University of Arizona, 2013.

R51. W. G. Mangold, E. Babakus, and K. T. Smith, "Trust and the online conversation: the case of online reviews," Internet Marketing and Advertising, vol. 8, pp. 143160, January 2013.

R52. D. Kim, "Under what conditions will social commerce business models survive?," Electronic Commerce Research and Applications, vol. 12, pp. 69-77, 2013.

R53. R. G. Curty, and P. Zhang, "Website features that gave rise to social commerce: a historical analysis," Electronic Commerce Research and Applications, vol. 12, pp. 260-279, 2013.

R54. G. C. Kane, M. Alavi, G. Labianca, and S. P. Borgatti, "What's Different About Social Media Networks? A Framework and Research Agenda, MIS Quarterly, vol. 38, pp. 1-68, January 2013.

R55. S-R. Yan, X-L. Zheng, Y. Wang, W. W. Song, and W-Y. Zhang, "A graph-based comprehensive reputation model: Exploiting the social context of opinion to enhance trust in social commerce," Information Sciences, vol. 318, pp. 51-72, October 2015.

R56. A. D. Noor, R. Sulaiman, and A. Abu Bakar, "A Review of Factors that Influenced Online Trust in Social Commerce," International Conference on Information Technology and Multimedia (ICIMU), November 18 - 20, Putrajaya, Malaysia, 2014.

R57. N. Hajli, "A study of the impact of social media on consumers," International Journal of Market Research, vol. 56, pp. 387-404, March 2014.

R58. K. P. K. Kumar, and G. Geethakumari, "A taxonomy for modeling and analysis of the diffusion of information in social networks," International Journal of Communication Networks and Distributed Systems, vol. 13, pp. 119-143.

R59. L. W. Pei, "Beyond Liking And Sharing: An Examination Of Consumers' Intentions To Use Facebook For Search And Evaluation," Master Thesis, University Tunku Abdul Rahman, 2014.

R60. Y-H. Fang, "Beyond the Credibility of Electronic Word of Mouth: Exploring eWOM Adoption on Social Networking Sites from Affective and Curiosity Perspectives," International Journal of Electronic Commerce, vol. 18, pp. 67-101, 2014.

R61. A. Chen, Y. Lu, P.Y.K. Chau, and S. Gupta, "Classifying, Measuring, and Predicting Users' Overall Active Behaviour on Social Networking Sites," Journal of Management Information Systems, vol. 31, pp. 213-253, 2014.

R62. Y. Wang, and N. Hajli, "Co-Creation in Branding through Social Commerce: The Role of Social Support, Relationship Quality, and Privacy Concerns," Twentieth Americas Conference on Information Systems, Savannah, pp. 1-16, August 2014. 
R63. C. Alaimo, "Computational Consumption: Social Media and the construction of Digital Consumers," Ph.D. Thesis, Department of Management of the London School of Economics, 2014.

R64. S. Hillebrand, "Content Marketing in Social Networks," Master Thesis, EMBS UNIVERSITÄT KASSEL, 2014.

R65. Y. Kim, Y. Chang, S. F. Wong, and M-C. Park, "Customer Attribution of Service Failure and Its Impact in Social Commerce Environment," International Journal of Electronic Customer Relationship Management, vol. 8, pp. 136-158, November 2014.

R66. A. N. Hidayanto, A. Herbowo, N. F. Ayuning Budi, and Y. G. Sucahyo, "Determinant of Customer Trust on E-Commerce and Its Impact on Purchase and Word OF Mouth Intention: A Case of Indonesia," Journal of Computer Science, vol. 10. pp. 2395-2407, 2014.

R67. A. R. Toure, "Diffusion of Social Network Technology and Overuse among Health Industry Knowledge Workers," Ph.D. Thesis, Walden University, 2014.

R68. S. Sharma, and R. E. Crossler, "Disclosing too much? Situational factors affecting information disclosure in the social commerce environment," Electronic Commerce Research and Applications, vol. 13, pp. 305-319, October 2014.

R69. C. M. M. De Figueiredo, "Emotions and Recommender Systems: A Social Network Approach," Ph.D. Thesis, Universidade do Porto, 2014.

R70. G. Jiang, F. Ma, J. Shang, and P. Y. K. Chau, "Evaluation of knowledge sharing behaviour in social commerce: An agent-based computational approach," Journal of Information Sciences, vol. 278, pp. 250-266, September 2014.

R71. Y. Xue, and L. Guo-Xin, (2014). "Exploring Social Commerce Adoption in China: A Uses and Gratification Perspective," 21th International Conference on Management Science \& Engineering, Helsinki, Finland, August 17-19, pp. 546554, 2014.

R72. I. J. Hwang, B. G., Lee, and K. Y., Kim, "Information Asymmetry, Social Networking Site Word of Mouth, and Mobility Effects on Social Commerce in Korea," Cyberpsychology, Behaviour, and Social Networking, vol. 17, pp. 117124, December 2014.

R73. S. K. Tanbeer, C. K. Leung, and J. J. Cameron, "Interactive Mining of Strong Friends from Social Networks and Its Applications in E-Commerce," Journal of Organizational Computing and Electronic Commerce, vol. 24, pp. 157-173, 2014.

R74. M. Shanmugam, and Y. Y. Jusoh, "Social Commerce from the Information Systems Perspective: A Systematic Literature Review," International Conference on Computer and Information Sciences (ICCOINS), Kuala Lumpur, pp. 1-6, June 2014.

R75. G. O. I. A. Boa-Ventura, "Social Features of Web Assisted TOBACCO Interventions (WATIS): Case Studies," Ph.D. Thesis, The University of Texas at Austin, 2014.

R76. N. Hajli, X. Lin, M. Featherman, and Y. Wang, "Social word of mouth How trust develops in the market," International Journal of Market Research, vol. 56, pp. 673-689, September 2014.

R77. S. Farivar, and Y. Yuan, "The Dual Perspective of Social Commerce Adoption," Proceedings of the Thirteenth Annual Workshop on HCI Research in MIS (SIGHCI 2014 Proceedings), Auckland, New Zealand, pp. 1-5, December 2014.

R78. K. Hodgdon, "The Great Big Beautiful Tomorrow: Rogers' Diffusion of Innovation and Social Media Communication for Disney's Carousel of Progress," Master Thesis, Central Michigan University, 2014. 
R79. N. Hajli, "The role of social support on relationship quality and social commerce," Technological Forecasting \& Social Change, vol. 87, pp. 17-27, 2014.

R80. Y. Sun, L. Liu, X. Peng, Y. Dong, and S. J. Barnes, "Understanding Chinese users' continuance intention toward online social networks: an integrative theoretical model," Electron Markets, vol. 24, pp. 57-66, 2014.

R81. V. Kumar, "Understanding Cultural Differences in Innovation: A Conceptual Framework and Future Research Directions," Journal of International Marketing, vol. 22, pp. 1-29.

R82. Z. Huang, and M. Benyoucef, "User preferences of social features on social commerce websites: An empirical study," Technological Forecasting \& Social Change, vol. 95, pp. 57-72, June 2015.

R83. Q. Qu, J. Qi, and Y. Tan, "User-Generated Content (UGC) Encountered Enterprise Generated Content (EGC): Quantifying the Impact of EGC on the Propagation of Negative UGC,".PACIS 2014 Proceedings, January 2014.

R84. H. Zhang, Y. Lu, S. Gupta, and L. Zhao, "What motivates customers to participate in social commerce? The impact of the technological environment and virtual customer experiences," Information \& Management, vol. 51, pp. 1017-1030, December 2014.

R85. H. Lee, and J. Choi, "Why do people visit social commerce sites but do not buy? The role of the scarcity heuristic as a momentary characteristic," KSII Transactions on Internet and Information Systems, vol. 8, pp. 2383-2399, July 2014.

R86. N. Hajli, M. Shanmugam, P. Powell, and P. E. D. Love, "A study on the continuance participation in on-line communities with social commerce perspective," Technological Forecasting \& Social Change, vol. 96, pp. 232-241, July 2015.

R87. H. Alhulai, M. Dick, and A. Abareshi, "An Investigation of Customers' Loyalty to Social Commerce Websites," 12th International Conference on e-Business (ICE-B-2015), pp. 88-93, January 2015.

R88. T. Friedrich, "Analyzing the Factors that Influence Consumers' Adoption of Social Commerce - A Literature Review," Twenty-first Americas Conference on Information Systems, Puerto Rico, USA, pp. 1-16, August 2015.

R89. K. Z. K. Zhang, M. Benyoucef, and S. J. Zhao, "Building brand loyalty in social commerce: The case of brand microblogs," Electronic Commerce Research and Applications, vol. 15, pp. 14-25, February 2016.

R90. N. Hajli, and X. Lin, "Consumer Adoption of Social Commerce," International Conference on HCI in Business (HCIB 2015), pp. 279-287, 2015.

R91. S. S. Abed, Y. K., Dwivedi, and M. D., Williams, "Consumers' Perceptions of Social Commerce Adoption in Saudi Arabia," Conference on e-Business, eServices and e-Society, pp.133-143, October 2015.

R92. H. H. Alshibly, "Customer Perceived Value in Social Commerce: An Exploration of Its Antecedents and Consequences," Journal of Management Research, vol. 7, pp. 17-37, January 2015.

R93. M. S. Balaji, K. K. Wei, and A. Y. L. Chong, "Determinants of Negative Wordof-Mouth Communication using Social Networking Sites," Information \& Management, vol. 53, pp. 528-540, June 2016.

R94. F. X. Yang, "Effects of Restaurant Satisfaction and Knowledge Sharing Motivation on EWOM Intention: The Moderating Role of Technology Acceptance Factors," Journal of Hospitality \& Tourism Research, vol. 41, pp. 1 -35, December 2013. 
R95. A. Chen, Y. Lu, and B. Wang, "Enhancing perceived enjoyment in social games through social and gaming factors," Information Technology \& People, vol. 29, pp. $99-119,2016$.

R96. Y. Y. Abdul Talib, and F. H. Rusly, "Falling Prey for Social Media Shopping Frauds: The Victims' Perspective," International Conference on E-Commerce 2015(ICoEC2015), Sarawak, Malaysia, pp. 1-7, October 2015.

R97. P-L. Teh, P. K. Ahmed, and G. K. Tayi, "Generation-Y shopping: the impact of network externalities and trust on the adoption of social commerce," International Journal of Electronic Business, vol. 12, pp.117-141, 2015.

R98. P. Ryden, T. Ringberg, and R. Wilke, "How Managers' Shared Mental Models of Business-Customer Interactions Create Different Sense making of Social Media," Journal of Interactive Marketing, vol. 31, pp. 1-16, 2015.

R99. R. Gruenbaum, "Making social technologies work: leveraging the power and managing perils of social technologies in business," Springer Publications, Business and Economics, 2016.

R100. L. Qin, and S. Kong, "Perceived Helpfulness, Perceived Trustworthiness, and Their Impact upon Social Commerce Users' Intention to Seek Shopping Recommendations," Journal of Internet Commerce, vol. 14, pp. 492-508, 2015.

R101. J. Yu, P. J-H. Hu, and T-H. Cheng, "Role of Affect in Self-Disclosure on Social Network Websites: A Test of Two Competing Models," Journal of Management Information Systems, vol. 32, pp. 239-277, 2015.

R102. F. Thomas, O. Sven, S. Sebastian, and E. Holger, "Selecting Technologies for Social Commerce: Towards a Systematic Method," Proceedings of the 23rd European Conference on Information Systems (ECIS), Münster, Germany, Paper 50, May 2015

R103. P. Verma, and S. Jain, "Skills Augmenting Online Shopping Behaviour: A Study of Need for Cognition Positive Segment," Business Perspectives and Research, vol. 3, pp. 126-145, 2015.

R104. S. S. Abed, Y. K. Dwivedi, and M. D. Williams, "Social Commerce Adoption by Saudi Consumers: A Conceptual Model," UK Academy for Information Systems Conference Proceedings 2015.Paper 6, 2015.

R105. N. Hajli, "Social commerce constructs and consumer's intention to buy," International Journal of Information Management, vol. 35, pp.183-191, 2015.

R106. E. Turban, "Electronic Commerce: A Managerial and Social Networks Perspective, Social Commerce: Foundations, Social Marketing, and Advertising Chapter," Springer Texts in Business and Economics, 2015.

R107. N. Hajli, and J. Sims, "Social commerce: The transfer of power from sellers to buyers," Technological Forecasting and Social Change, vol. 94, pp. 350 -358, 2015.

R108. A. Adeleye, "Social Media Marketing; The Case of Africa. Challenges of Social Media Marketing In Africa," Master Thesis, Carleton University, 2015.

R109. P. I. P. Lasserre, "Social Networks and Mobile Money Adoption: A quantitative case study in Uganda," Master Thesis, Eindhoven University of Technology, 2015.

R110. V. Rassega, O. Troisi, C. Torre, V. Cucino, A. Santoro, and N. Prudente, "Social Networks and the Buying Behaviour of the Consumer," Journal of Global Economics, vol. 3, pp. 1-6, 2015

R111. L. K. Sang, "The impact of social media initiatives on operational and financial outcomes: two empirical studies," Ph.D. Thesis, Hong Kong Polytechnic University, 2015. 
R112. K. F. Hashim, S. A. M. Yusof, and R. Ahmad, "The Influence of Hedonic Values on S-commerce Adoption Behaviour," Advanced Science Letters, vol. 21, pp. 1561-1565, 2015.

R113. M. Alisic, O. Netterström, and A. Tropp, "The Influence of Online Social Ties on Consumers' Purchase Intentions: eWOM in the Case of Swedish Blog Readers," Bachelor Thesis, Jonkoping University, 2015.

R114. S. Mamonov, and R. Benbunan-Fich, "To Give or Not to Give? An Exploratory Study of User Beliefs Influencing Adoption of Facebook Gifts," 48th Hawaii International Conference on System Sciences, 2015.

R115. J. H. Joo, "Understanding Korean College Students' Social Commerce Behaviour through an Integrated Model of Technology Readiness, Technology Acceptance Model, and Theory of Planned Behaviour," Journal of Digital Convergence, vol. 13, pp. 99-107, July 2015.

R116. N. A. B. Mukhtar, "Understanding the Determinants of S-Commerce Adoption: From Unified Theory of Acceptance and Use of Technology (UTAUT) Perspective," Master Thesis, University of Utara Malaysia, 2015.

R117. J. Kim, and H. Lee, "VADA: Wi-Fi Direct Based Voluntary Advertisement Dissemination Algorithm for Social Commerce Service," 2015 IEEE 81st Vehicular Technology Conference (VTC Spring), Glasgow, 2015, pp. 1-6.

R118. J. Hamari, and J. Koivisto, "Working out for likes: An empirical study on social influence in exercise gamification," Computers in Human Behaviour, vol. 50, pp. 333-347, 2015.

R119. L. Chen, and R. Wang, "A Trust Evaluation Model for Social Commerce Based on BP Neural Network," Journal of Data Analysis and Information Processing, vol. 4, pp. 147-158, 2016.

R120. M. Dashti, A. Sanayei, H. Rezai Dolatabadi, and M. H. Moshrefjavadi, "An Analysis of Factors Affecting Intention to Purchase Products and Services in Social Commerce," Modern Applied Science, vol. 10, pp. 98-106, 2016.

R121. S. S. Abed, "An Empirical Examination of Factors Affecting Continuance Intention Towards Social Networking Sites," Conference on e-Business, eServices and e-Society, pp. 228-239, September 2016.

R122. P. Ifinedo, "Applying uses and gratifications theory and social influence processes to understand students' pervasive adoption of social networking sites: Perspectives from the Americas," International Journal of Information Management, vol. 36, pp. 192-206, 2016.

R123. K. Z. K. Zhang, and M. Benyoucef, "Consumer behaviour in social commerce: A literature review," Decision Support Systems Journal, vol. 86, pp. 95-108, June 2016.

R124. S. Seol, H. Lee, J. Yu, and H. Zo, "Continuance usage of corporate SNS pages: A communicative ecology perspective," Information \& Management Journal, vol.53, pp. 740-751, September 2016.

R125. W. Nadeem, "Examining Consumers' Acceptance of Social Commerce in Clothing E-Retail," Ph.D. Thesis, University of Oulu, 2016.

R126. J. V. Chen, B-C. Su, and A. E. Widjaja, "Facebook C2C social commerce: A study of online impulse buying," Decision Support Systems, vol. 83, pp. 57-69, 2016.

R127. I. Akman, and A. Mishra, "Factors influencing consumer intention in social commerce adoption," Information Technology \& People, vol. 30, pp. 356-370, 2017. 
R128. Y. Diao, Y. He, and Y. Yuan, "Framework for Understanding the Business Model of Social Commerce," International Journal of Management Science, vol. 2, pp. 112-118, 2015.

R129. Á. Plaza-Lora, and Á. F. Villarejo-Ramos, "Hedonic and Utilitarian Effects on the Adoption and Use of Social Commerce," XXVI Jornadas Luso-Espanholas de Gestâo Científica Conference, Castelo Branco, Portugal, February 2016.

R130. E. Turban, "Social Commerce: Marketing, Technology, and Management, Implementing Social Commerce Systems Chapter," Springer Texts in Business and Economics, 2016.

R131. A. B. Adam, J. E. B. M. Jizat, and M. A. B. Mohd Nor, "Internal Factors within Entrepreneurs that Influence the Acceptance and Use of Social Commerce among SMEs in Malaysia," DeReMa Jurnal Manajemen, vol. 11, pp. 35-45, 2016.

R132. J-J. Hew, V-H. Lee, K-B. Ooi, and B. Lin, "Mobile social commerce: The booster for brand loyalty?," Computers in Human Behaviour, vol 59, pp. 142-154, 2016.

R133. Y-H. Lin, C-L. Hsu, M-F. Chen, and C-H. Fang, "New gratifications for social word-of-mouth spread via mobile SNSs: Uses and gratifications approach with a perspective of media technology,". Telematics and Informatics, vol. 34, pp. 382397, July 2017.

R134. F. J. Martı'nez-Lopez, R. Anaya-Sa'nchez, R. Aguilar-Illescas, and S. Molinillo, "Online Brand Communities Using the Social Web for Branding and Marketing," Springer International Publishing, 2016.

R135. A. Gonzalez, "Opinion leaders in the new social environment A Youtube case on social media opinion leaders," Bachelor Thesis, Linnaus University, 2016.

R136. C-D. Chen, Q, Zhao, and J-L. Wang, "Psychological Ownership: an Empirical Study on ITS Antecedents and Impacts upon Social Media Loyalty," PACIS 2016 Proceedings. Paper 179, 2016.

R137. Y. Hou, H. Chen, and S. Yang, "Research on the Business Model of E-commerce Platform based on Value Co-creation Theory," International Journal of u and eService, Science and Technology, vol. 9, pp. 415-424, 2016.

R138. M. Kubiak, and A. Lindberg, "A study exploring Swedish young women`s views and responses to the marketing of Aesthetic Surgery in social media," Bachelor Thesis, School of Health and Society, Kristianstad University, 2016.

R139. S. S. Abed, Y. K. Dwivedi, and M. D. Williams, "Social commerce as a business tool in Saudi Arabia's SMEs," Indian Culture and Business Management, vol. 13, pp. 1-19, 2016.

R140. C. Baethge, J. Klier, and M. Klier, "Social commerce-state-of-the-art and future research directions," Electron Markets, vol. 26, pp. 269-290, 2016.

R141. A. Toker, M. Seraj, A. Kuscu, R. Yavuz, S. Koch, and C. Bisson, "Social media adoption: A process-based approach," Journal of Organizational Computing and Electronic Commerce, vol. 26, pp. 344-363, 2016.

R142. S. Edin, B. Albert, and L. David, "Social Media Disruptive Change in Healthcare: Responses of Healthcare Providers?," Research-in-Progress Papers. Paper 17, 2016.

R143. E. Turban, "Social Commerce: Marketing, Technology and Management, Strategy and Performance Management in Social Commerce Chapter," Springer Texts in Business and Economics, 2016.

R144. E. Turban, "Social Commerce: Marketing, Technology, and Management Supporting Theories and Concepts for Social Commerce Chapter," Springer Texts in Business and Economics, 2016. 
R145. M. Shanmugam, S. Sun, A. Amidi, F. Khani, and F. Khani, "The applications of social commerce constructs," Information Management, vol. 36, pp. 425-432, 2016.

R146. H. Beyari, and A. Abareshi, "The Conceptual Framework of the Factors Influencing Consumer Satisfaction in Social Commerce," Proceedings of the Australia-Middle East Conference on Business and Social Sciences 2016, DubaiUAE, pp. 505-514, April 2016.

R147. N. Vongsraluang, and V. Bhatiasevi, "The determinants of social commerce system success for SMEs in Thailand," Information Development, vol. 33, pp. 117, March 2016.

R148. G. Kodippili, M. T. N. Jayawickrama, O. W. D. Y. Yugandari, S. D. H. Pamudini, and H. M. U. S. R. Samarasinghe, "The Influence of Social Media Marketing on Customer Loyalty towards Clothing Stores", National Conference on Technology and Management (NCTM-2016), pp. 59-68, April 2016.

R149. S. Frigui, "The Ubiquitous Role of New Social Media Channels and Innovative Mobile Services: Are Consumers Ready?," Ph.D. Thesis, University di Bologna, 2016.

R150. E. Turban, "Social Commerce: Marketing, Technology and Management, Tools and Platforms for Social Commerce Chapter," Springer Texts in Business and Economics, 2016.

R151. L. Chen, and R. M. Wang, "Trust Development and Transfer from Electronic Commerce to Social Commerce: An Empirical Investigation,". American Journal of Industrial and Business Management, vol. 6, pp. 568-576, 2016.

R152. H. Abdelsalam, A. B. Busalim, and R. C. Hussin, "Understanding social commerce: A systematic literature review and directions for further research," International Journal of Information Management, vol. 36, pp. 1075-1088, 2016.

R153. J. Martins, R. Goncalves, T. Oliveira, M. Cota, and F. Branco, "Understanding the determinants of social network sites adoption at the firm level: A mixed methodology approach," Electronic Commerce Research and Applications, vol. 18, pp. 10-26, 2016.

R154. D. Manika, S. Papagiannidis, and M. Bourlakis, "Understanding the effects of a social media service failure apology: A comparative study of customer vs. potential customers," International Journal of Information Management, vol. 37, pp. 214-228, June 2017.

R155. F. Thomas, O. Sven, and S. Sebastian, "Unveiling the Impacts of Social Commerce Features - an Integrated Research Model," Twenty-Fourth European Conference on Information Systems (ECIS), İstanbul, Turkey, June 2016.

R156. S. Altinişik, and S. Özkan Yildirim, "Consumers' Adoption of Social Commerce: A Systematic Literature Review," Mugla Journal of Science and Technology, vol. 3, pp. 131-137, 2017.

R157. F. Thies, M. Wessel, and A. Benlian, "Effects of Social Interaction Dynamics on Platforms," Journal of Management Information Systems, vol. 33, pp. 843-873, December 2016.

R158. S. Mamonov, and R. Benbunan-Fich, "Exploring factors affecting social ecommerce service adoption: The case of Facebook Gifts," International Journal of Information Management, vol. 37, pp. 590-600, 2017.

R159. E. Turban, "Introduction to Electronic Commerce and Social Commerce, Overview of Electronic Commerce and Social Commerce Chapter," Springer Texts in Business and Economics, 2017. 
R160. E. Turban, "Introduction to Electronic Commerce and Social Commerce, Social Commerce: Foundations, Social Marketing, and Advertising Chapter," Springer Texts in Business and Economics, 2017.

R161. E. Turban, "Introduction to Electronic Commerce and Social Commerce, Social Enterprise and Other Social Commerce Topics Chapter," Springer Texts in Business and Economics, 2017.

R162. S. Yoon, "Social media, information presentation, consumer involvement, and cross-border adoption of pop culture products," Electronic Commerce Research and Applications, vol. 27, pp. 129-138, February 2018

R163. A. M. Aladwani, "A quality-facilitated socialization model of social commerce decisions," International Journal of Information Management, vol. 40, pp. 1-7, 2018.

R164. N. Aghakhani, J. Karimi, and M. Salehan, "A Unified Model for the Adoption of Electronic Word of Mouth on Social Network Sites: Facebook as the Exemplar," International Journal of Electronic Commerce, vol. 22, pp. 202-231, 2018.

R165. T. Tuten, and A. Mintu-Wimsatt, "Advancing Our Understanding of the Theory and Practice of Social Media Marketing: Introduction to the Special Issue," Journal of Marketing Theory and Practice, vol. 26, pp. 1-3, 2018.

R166. M. Tajvidi, M-O. Richard, Y. Wang, and N. Hajli, "Brand co-creation through social commerce information sharing: The role of social media," Journal of Business Research, DOI: 10.1016/j.jbusres.2018.06.008.

R167. A. M. Baabdullah, "Consumer adoption of mobile social network games in Saudi Arabia: The role of social influence, hedonic motivation, and trust," Technology in Society, vol. 53, pp. 91-102, May 2018.

R168. Q. Li, N., Liang, and E. Y. Li, "Does Friendship Quality Matter in Social Commerce? An Experimental Study of Its Effect on Purchase Intention," Electronic Commerce Research, vol. 18, pp. 693-717, 2018.

R169. C. Maia, G. Lunardi, A. Longaray, and P. Munhoz, "Factors and characteristics that influence consumers' participation in social commerce," Revista de Gestão, vol. 25, pp. 194-211, 2018.

R170. I. Akman, and A. Mishra, "Factors influencing consumer intention in social commerce adoption," Information Technology \& People, vol. 30, pp. 356-370, June 2017.

R171. A. Hilal, D. Martin, and A. Ahmad, "Factors that Impact Customers' Loyalty to Social Commerce Websites," 2018 International Conference on Information Resources Management, Ningbo, China, pp. 1-13, June 2018

R172. B. Osatuyi, and H. Qin, "How vital is the role of affect on post-adoption behaviours? An examination of social commerce users," International Journal of Information Management, vol. 40, pp. 175-185, 2018.

R173. A. S. Yusuf, Ab. Razak, C. Hussin, and A. H. Busalim, "Influence of e-WOM engagement on consumer purchase intention in social commerce," Journal of Services Marketing, vol. 32, pp. 493-504, July 2018.

R174. I. B. Yahia, N. Al-Neama, and L. Kerbache, "Investigating the drivers for social commerce in social media platforms: Importance of trust, social support, and the platform perceived usage," Journal of Retailing and Consumer Services, vol. 41, pp. 11-19, 2018.

R175. S-Y. Hung, A. P-I. Yu, and Y-C. Chiu, "Investigating the factors influencing small online vendors' intention to continue engaging in social commerce," 
Journal of Organizational Computing and Electronic Commerce, vol. 28, pp. 930, 2018.

R176. Y. Cui, J. Mou, and Y. Liu, "Knowledge mapping of social commerce research: a visual analysis using CiteSpace," Electronic Commerce Research, vol. 18, pp. 837-868, January 2018.

R177. Y-L. Wu, and E. Y. Li, "The marketing mix, customer value, and customer loyalty in social commerce: A stimulus-organism-response perspective," Internet Research, vol. 28, pp. 74-104, 2018.

R178. J. M. Hansen, G. Saridakis, and V. Benson, "Risk, Trust, and the Interaction of Perceived Ease of Use and Behavioural Control in Predicting Consumers' Use of Social Media for Transactions," Computers in Human Behavior, vol. 80, pp. 197206, March 2018.

R179. N. Sangi, L., Shuguang, and A. R. Sangi, "Robustness of Factors Influencing Social Media Usage/Adoption amongst SMEs in Developing Countries: A Case of Pakistan," IC4E 2018, January 11-13, San Diego, CA, USA, 2018.

R180. H. Han, H. Xu, and H. Chen, "Social commerce: A systematic review and data synthesis," Electronic Commerce Research and Applications, vol. 30, pp. 38-50, 2018.

R181. M. D. Williams, "Social Commerce and the Mobile Platform: Payment and Security Perceptions of Potential Users," Computers in Human Behaviour, DOI: 10.1016/j.chb.2018.06.005.

R182. J. C. Mendoza-Tello, H. Mora, F. A. Pujol-Lopez, and M. D. Lytras, "Social Commerce as a Driver to Enhance Trust and Intention to Use Cryptocurrencies for Electronic Payments," IEEE Access, vol. 6, pp. 50737-50751, 2018, DOI: 10.1109/ACCESS.2018.2869359..

R183. O. Gibreel, D. A. Alotaibi, and J. Altmann, "Social commerce development in emerging markets," Electronic Commerce Research and Applications, vol. 27, pp. 152-162, 2018.

R184. A. S. Arora, "Social Commerce Optimization: An Integrated Framework for Consumer Behaviour in Social Media," Global Business Value Innovations, International Marketing and Management Research book series, Springer Publication, 2018.

R185. H-C. Ko, "Social desire or commercial desire? The factors driving social sharing and shopping intentions on social commerce platforms," Electronic Commerce Research and Applications, vol. 28, pp. 1-15, 2018.

R186. B. Sarmah, S. Kamboj, and J. Kandampully, "Social media and co-creative service innovation: an empirical study," Online Information Review, vol. 42, pp. 1146-1179, November 2018.

R187. S. Abed, Y. Dwivedi, and M. Williams, "Social Media as a Bridge to Ecommerce Adoption in SMEs: A Systematic Literature Review," The Marketing Review, vol. 15, pp. 39-57, 2015.

R188. A. S. Arora, "Global Business Value Innovations, Social Media Driven StudentCentered Learning Through Social Commerce in Higher Education Chapter", International Marketing and Management Research book series, Springer Publication, 2018.

R189. C. Murendo, M. Wollni, A. De Brauw, and N. Mugabi, "Social Network Effects on Mobile Money Adoption in Uganda," The Journal of Development Studies, vol. 54, pp. 327-342, March 2017.

R190. D. Corkindale, J. Ram, and H. Howard Chen, "The adoption of Firm Hosted Online Communities: an empirical investigation into the role of service quality 
and social interactions," Enterprise Information Systems, vol. 12, pp. 173-195, 2017.

R191. E. W. Lubua, and P. Pretorius, "The Impact of Demographic Factors to the Adoption of Social Commerce in Tanzania," IST-Africa 2018 Conference Proceedings, Gaborone, Botswana, May 2018.

R192. B. Sarmah, S. Kamboj, and J. Kandampully, "Social media and co-creative service innovation: an empirical study," Online Information Review, vol. 42, pp. 1146-1179, November 2018.

R193. C-Y. Li, and Y-C. Ku, "The Power of a Thumbs-Up: Will E-commerce Switch to Social Commerce?," Information and Management, vol. 55, pp. 340-357, April 2018.

R194. A. Wongkitrungrueng, and N. Assarut, "The role of live streaming in building consumer trust and engagement with social commerce sellers," Journal of Business Research, vol. 117, pp. 543-556, September 2020.

R195. A. Y-L. Chong, E. Lacka, L. Boying, and H. K. Chan, "The Role of Social Media in Enhancing Guanxi and Perceived Effectiveness of E-commerce Institutional Mechanisms in Online Marketplace," Information \& Management, vol. 55, pp. 621-632, July 2018.

R196. H. Masoodul, I. Zeeshan, and K. Bakhtawar, "The role of trust and social presence in social commerce purchase intention," Pakistan Journal of Commerce and Social Sciences (PJCSS), vol.12, pp. 111-135, 2018.

R197. C-H. Yu, C-C. Tsai, Y. Wang, K-K. Lai, and M. Tajvidi, "Towards Building a Value Co-Creation Circle in Social Commerce," Computers in Human Behaviour, vol. 108, July 2020, DOI: 10.1016/j.chb.2018.04.021.

R198. J. Lin, L. Li, Y. Yan, and O. Turel, "Understanding Chinese consumer engagement in social commerce: The roles of social support and swift guanxi," Internet Research, vol. 28, pp. 2-22, February 2018.

R199. L-Y. Leong, N. I. Jaafar, and S. Ainin, "Understanding Facebook Commerce (FCommerce) Actual Purchase from an Artificial Neural Network Perspective," Journal of Electronic Commerce Research, vol. 19, pp. 75-103, February 2018.

R200. A. AlSharji, S. Z. Ahmad, and A. R. Abu Bakar, "Understanding social media adoption in SMEs: Empirical evidence from the United Arab Emirates," Journal of Entrepreneurship in Emerging Economies, vol. 10, pp. 302-328, June 2018.

R201. F. P. Tajudeen, N. I. Jaafar, and S. Ainin, "Understanding the impact of social media usage among organizations," Information \& Management Journal, vol. 55, pp.308-321, April 2018.

R202. L. Qin, Y. Kim, and X. Tan, "Understanding the Intention of Using Mobile Social Networking Apps Across Cultures," International Journal of HumanComputer Interaction, vol. 34, pp. 1183-1193, January 2018.

R203. J. Lin, Z. Luo, X. Cheng, and L. Li, "Understanding the interplay of social commerce affordances and swift guanxi: An empirical study," Information and Management, vol. 56, pp. 213-224, March 2019. 